\title{
28 Research Square

\section{Study on the Uptake of Aqueous Zinc Ion Onto a Novel Organic Acid Modified Biosorbent}

\section{Chukwunonso 0. Aniagor}

Nnamdi Azikiwe University Faculty of Engineering Technology

D. M. Hussein

Sebha University

S. Farag

National Research Centre

Ali Hashem ( $\nabla$ alihashem2000@yahoo.com )

National Research Centre https://orcid.org/0000-0001-7981-4872

\section{Research Article}

Keywords: Adsorption, Zinc ion, biosorbent, adsorption mechanism, adsorption modelling

Posted Date: June 18th, 2021

DOl: https://doi.org/10.21203/rs.3.rs-456826/v1

License: (c) (i) This work is licensed under a Creative Commons Attribution 4.0 International License. Read Full License 
Study on the uptake of aqueous zinc ion onto a novel organic acid modified biosorbent

${ }^{a}$ Department of Chemical Engineering, Nnamdi Azikiwe University, P.M.B. 5025, Awka, Nigeria.

${ }^{b}$ Chemistry Department, Faculty of Science, Sebha University, Sebha, Libya.

${ }^{c}$ Textile Research Division, National Research Centre, Dokki, Cairo, Egypt.

\section{*Corresponding author:}

Email address: co.aniagor@unizik.edu.ng

Telephone no: $+234-8061232153$

\section{***Corresponding author:}

Email address: alihashem2000@yahoo.com

Telephone no: 00202-3371362 Ext. 2039

Fax: 00202-3370931

\section{ORCID}

Chukwunonso O. Aniagor: http://orcid.org/0000-0001-6488-3998

A. Hashem: https://orcid.org/0000-0001-7981-4872

\section{Abstract}

Alhagi Graecorum $(A G)$ is an invasive plant with a massive/robust root structure that can grow up to 12 feet into the ground. The present study exploited the rich cellulosic content in this ' $A G$ ' root for the synthesis of a novel biosorbent ( ' $M A$ '). This low-cost biosorbent, with high carboxyl content of 447.22 (m. eq /100 g sample) was utilised for aqueous zinc ion sequestration. The surface functional groups and textural characteristics required for an efficient heavy metal binding was identified on ' $M A$ ' using Fourier transform infrared spectroscopy (FTIR) and scanning electron microscopy (SEM). Sip isotherm emerged as the model of best fit for equilibrium studies, hence, $\mathrm{Zn}$ (II) ion sorption onto ' $M A$ ' is believed to occur via a hybrid blend of homogenous monolayer and heterogeneous multilayer adsorption. Meanwhile, the Elovich $(\mathrm{SNE}=1.0429)$, intraparticle diffusion $(\mathrm{SNE}=1.0205)$ and pseudo- 
first-order $(\mathrm{SNE}=1.0455)$ provided the best fitting for 200,400 and $600 \mathrm{mg} / \mathrm{L}$ adsorption system, respectively. The maximum adsorption capacity of $188.67 \mathrm{mg} / \mathrm{g}$ was recorded at optimum adsorption conditions, with the predominance of the electrostatic and electron-donoracceptor interaction mechanism. The abundant surface oxygenous functional groups on ' $M A$ ' positively influenced its adsorption capacity; thus, making it a promising biosorbent for aqueous Zn (II) uptake.

Keyword: Adsorption; Zinc ion; biosorbent; adsorption mechanism; adsorption modelling

\section{Introduction}

$\mathrm{Zn}(\mathrm{II})$ is an essential element for healthy living when retained within the permissible contamination limits (Jagaba et al., 2020). A maximum permissible limit of $5 \mathrm{mg} / \mathrm{L}$ was stipulated by the World Health Organization (WHO) and the United States Environmental Protection Agency (USEPA) for Zn(II) in drinking water (Jagaba et al., 2020). The existence of $\mathrm{Zn}$ (II) ion above these stipulated limits could result in varying degrees of health challenges (Barakat, 2011; Wołowiec et al., 2019). Meanwhile, zinc ion contamination occurs mainly via inappropriate disposal of chemical process industrial effluents into the aquatic environment (Badruddoza et al., 2013; Chen et al., 2018) and their efficient removal pose a serious challenge to researchers and the scientific community.

Several technologies (Awual, Hasan, Asiri, et al., 2019; Badruddoza et al., 2013; Matouq et al., 2015; Wołowiec et al., 2019) have been applied for heavy metal uptake from an aqueous environment. However, some of these technologies have associated limitations like low treatment efficiency, high energy and cost requirement, non-eco-friendly, etc (Awual, 2016; Awual, Hasan, Islam, et al., 2019; Shahat, Hassan, Azzazy, et al., 2018; Shahat, Hassan, ElShahat, et al., 2018). In this work, the biosorption technique using a low-cost biosorbent precursor was explored for the uptake of aqueous zinc ion. The preference for the biosorption 
approach is related to its operational flexibility, process efficiency, efficient regeneration of spent adsorbent, etc (Al-Shaalan et al., 2019; Ali et al., 2019; Ali et al., 2018; Awual et al., 2017). Consequently, a variety of biosorbents such as fungal mycelial wastes (Luef et al., 1991), Rice bran (Wang et al., 2006), Azadirachta indica bark (King et al., 2008), immobilized Candida utilis and Candida tropicalis cells (Ahmad et al., 2013), rapeseed waste (Paduraru et al., 2015), have been successfully applied for aqueous zinc ion uptake. Also, the Eichhornia crassipes biomasses were successfully applied for the uptake of copper ion (Abdelraheem $e t$ al., 2017; Abdelraheem et al., 2016; Komy et al., 2013). Meanwhile, the efficacy of a novel biosorbent ('MA') for zinc ion uptake was investigated in this study.

Alhagi Graecorum is an invasive tropical plant that often serves as animal fodder, but its elimination from invaded farmland could be very challenging (Ebrahimi et al., 2015). Considering its invasiveness, relative availability and rich cellulosic content, Alhagi Graecorum adoption as the choice of adsorbent precursor in this study is justified. Furthermore, the novel biosorbent ('MA') was obtained through dual reaction stages of direct carbonylation of hydroxyl groups, $-\mathrm{OH}$ (using succinic acid) and subsequent esterification of the resultant anhydride analogue into ester of high carboxyl $(-\mathrm{COOH})$ content. The characteristics of the biosorbent precursor and its modifier are complementary in certain ways. The Alhagi Graecorum plant is readily available but with limited carboxyl groups availability, hence its poor metal ion sorption capacity, while the esterification agent (succinic acid) is a liquid and cannot be applied as a sole adsorbent. The aqueous zinc ion sorption ability of the novel biosorbent was subsequently evaluated under batch mode. The surface chemistry, elemental distribution and morphological features of the synthesized adsorbent were obtained, while the effect of various process variable on the adsorption capacity was elucidated in the study. 


\section{Materials and methods}

80

\subsection{Materials}

The Alhagi Graecorum $(A G)$ plant was obtained from the Matrouh desert, Egypt. The root of this plant was separated from the stems and leaves, and the latter was discarded. The root material was carefully washed with distilled water to remove every adherent earth particle and then oven-dried at $80{ }^{\circ} \mathrm{C}$ for $10 \mathrm{~h}$. The dried root material was subsequent ground and sieving to a particle size of 50-125 $\mu \mathrm{m}$. All reagents used in this study; zinc acetate, EDTA, succinic acid, acetic acid, sodium carbonate, acetone, and ethyl alcohol were all laboratory grade chemicals, supplied by Merck, Germany.

\subsection{Preparation of the adsorbent}

The novel adsorbent (MA) was synthesized as follow; $2 \mathrm{~g}$ of the Alhagi Graecorum $(A G)$ powder was added to a beaker containing an aqueous solution of succinic acid whose volume is sufficient enough to achieve a slurry. The mixture was manually stirred using a spatula to achieve homogeneity. Afterwards, the homogeneous slurry was oven-dried (at $100-150{ }^{\circ} \mathrm{C}$ ) and subsequently cooled to room temperature to obtain ' $M A$ '. The dried ' $M A$ ' sample was washed with ethanol/water solution (80:20) to get rid of any unreacted acid/soluble byproducts, followed by oven-drying at $80{ }^{\circ} \mathrm{C}$ for $6 \mathrm{~h}$.

\subsection{Adsorbent characterization}

\subsubsection{Fourier Transform Infrared (FTIR) spectroscopy}

To elucidate the inherent functional groups on the biosorbent precursor and the synthesized biosorbent, the FTIR spectra studies were conducted. The IR spectra were recorded at the wavelength range of $4000-400 \mathrm{~cm}^{-1}$ using Perkin-Elmer, Shimadzu FTIR-8400S spectrophotometer. 
103

104

The surface morphologies of the adsorbent precursor, synthesized biosorbent and the spent adsorbent were explained via SEM micrograph obtained using Scanning Electron Microscope, Model JEOL-JSM-5600 (operating at accelerating voltage of $25.00 \mathrm{kV}$ ). During the analysis, the respective biosorbent samples were placed on the microscope stub and coated with a thin gold layer using a polaron diode sputter unit. Consequently, the energy dispersive X-ray (EDX) mapping detector (Model JEOL-JSM-5600) attached to the SEM equipment was used for studying the biosorbents' elemental distribution.

\subsubsection{The $\mathrm{pH}$ at zero charge (pHpzc) determination}

The point of zero charge $\left(\mathrm{pH}_{\mathrm{pzc}}\right)$ of the biosorbent was obtained following the procedure earlier reported by Khalil et al. (1990) and Noh et al. (1990). In the procedure, the $\mathrm{pH}$ of $100 \mathrm{ml}$ of $0.01 \mathrm{~N} \mathrm{NaCl}$ solution each contained in a separate conical flask was adjusted in the initial range of $\mathrm{pH} 2.0$ to $\mathrm{pH} 12.0$, using a suitable volume of $0.01 \mathrm{~N} \mathrm{HCl}$ or $0.01 \mathrm{~N} \mathrm{NaOH}$ solution. After noting the initial of the solution contained in the different conical flasks, about $0.1 \mathrm{~g}$ of the biosorbent sample was introduced into each of the flasks followed by reaction for $24 \mathrm{~h}$. Subsequently, the final $\mathrm{pH}$ of the solutions in the different flasks was measured and recorded. Then, the recorded initial $\mathrm{pH}$ values were plotted against the change in $\mathrm{pH}$ as shown in Fig. 4a

\subsection{Carboxyl content estimation}

$0.2 \mathrm{~g}$ of the ' $M A$ ' was added to $50 \mathrm{~mL}$ of $\mathrm{NaOH}$ solution $(0.03 \mathrm{~N})$ contained in a conical flask. The flasks and their content were allowed to equilibrate at $25{ }^{0} \mathrm{C}$ overnight. By titrating the content of the flask with $0.01 \mathrm{~N} \mathrm{HCl}$ solution. The carboxyl content of ' $M A$ ' was determined via titration with $0.01 \mathrm{~N} \mathrm{HCl}$ solution using phenolphthalein indicator (Khalil et al., 1990) and further evaluated using Eq. (1). 
Where $\mathrm{V}_{\mathrm{o}}=$ Volume of $\mathrm{HCl}$ consumed for the blank experiment $(\mathrm{mL}), \mathrm{V}_{1}=\mathrm{HCl}$ volume $(\mathrm{mL})$ consumed by the adsorbent sample, $\mathrm{N}=$ normality of the $\mathrm{HCl}$ solution, and $\mathrm{W}=$ mass of the ' $M A$ ' (g).

\subsection{Batch Adsorption Studies}

A specific amount of ' $M A$ ' $(0.03 \mathrm{~g})$ was contacted with $100 \mathrm{~mL}$ of a $\mathrm{Zn}$ (II) ion solution in a $125 \mathrm{~mL}$ Erlenmeyer flask. The solution $\mathrm{pH}$ was rightly tuned using either $0.1 \mathrm{M} \mathrm{HNO}_{3}$ or 0.1 $\mathrm{M} \mathrm{NaOH}$. After a certain period of agitation (at $150 \mathrm{rpm}, 30^{\circ} \mathrm{C}$ ), the mixture was filtered using Whatman No. 41 paper to separate the adsorbent and metal ion solution. The variation in the $\mathrm{Zn}$ (II) ion concentration was obtained from the direct titration with a standard EDTA solution. The effect of process variables on the ' $M A$ ' adsorption capacity was conducted by varying the agitation time from $0-180 \mathrm{~min}$, adsorbent mass from $0.3-7.0 \mathrm{~g} / \mathrm{L}$ and adsorbate solution temperature from $30-60{ }^{\circ} \mathrm{C}$. Meanwhile, the relevant parameters (amount adsorbed at equilibrium, $\mathrm{q}_{\mathrm{e}}$, and removal efficiency, R.E \%) derivable from the adsorption experiment was evaluated with Eqs. (2) - (3). For the avoidance of experimental error, a duplicate version of the respective batch adsorption and effect of process variable experiments were conducted and the accurate mean values for $\mathrm{q}_{\mathrm{e}}$ obtained in each case.

$$
\mathrm{q}_{\mathrm{e}}=\frac{\left(\mathrm{C}_{\mathrm{o}}-\mathrm{C}_{\mathrm{e}}\right) \mathrm{V}}{\mathrm{W}}
$$

$$
\mathrm{RE}(\%)=\frac{\mathrm{C}_{\mathrm{o}}-\mathrm{C}_{\mathrm{e}}}{\mathrm{C}_{\mathrm{o}}} \cdot 100 \%
$$

Where $\mathrm{C}_{\mathrm{o}}=$ Initial $\mathrm{Zn}$ (II) concentration $\left(\mathrm{mg} \mathrm{L}^{-1}\right), \mathrm{C}_{\mathrm{e}}=\mathrm{Zn}$ (II) concentration at equilibrium $\left(\mathrm{mg} \mathrm{L}^{-1}\right), \mathrm{W}=$ adsorbent mass $(\mathrm{g}), \mathrm{V}=$ volume of $\mathrm{Zn}$ (II) solution used (L). 
Insight into the adsorbate - adsorbent interaction during the adsorption process is obtained from adsorption isotherm modelling, while the various model parameters could inform the probable sorption mechanism (Abonyi et al., 2019; Menkiti, Abonyi, et al., 2018; Vargas et al., 2012).

The experimental equilibrium data generated from this study were modelled with nonlinear form of Langmuir (Hashem et al., 2016; Hashem, Badawy, et al., 2020; Langmuir, 1916), Freundlich (Freundlich, 1907; Ighalo et al., 2020; Igwegbe, Onukwuli, et al., 2020), Temkin (Menkiti, Aniagor, et al., 2018; Temkin, 1940), D-R (Foo et al., 2010; Hashem, Nasr, et al., 2020), Khan (ANIAGOR et al., 2020; Khan et al., 1997), Redlich-Peterson (Menkiti \& Aniagor, 2018; Redlich et al., 1959), Toth (Schweitzer et al., 2018; Toth, 1971) and Sips (ANIAGOR et al., 2020; Yan et al., 2019) models. The mathematical expression of these isotherm models is presented in Table 1. Similarly, the dynamics and kinetics involved in the present sorption process were studied using pseudo-first-order (Aniagor et al., 2018; Hashem et al., 2015), pseudo-second-order (Aniagor et al., 2019; Hashem et al., 2011), Elovich (Menkiti, Aniagor, et al., 2018), intraparticle diffusion (Hashem, Fletcher, et al., 2020; Menkiti, Abonyi, et al., 2018) and Bangham (Aniagor et al., 2018) kinetic models. The kinetic model equations are also presented in Table 2.

The nonlinear model goodness of data fit is usually evaluated from the magnitude of some dedicated goodness-of-fit (GO-Fm) models. The goodness of fit evaluation is made based on applied in this work comprised of average relative error, ARE (Marquardt, 1963), average percentage error, APE (Khair et al., 2017), the sum of squared error, SSE (Ng et al., 2002), hybrid fraction error, HYBRID (Kapoor et al., 1989), Marquardt's Percent Standard Deviation, 
172 determination, $\mathrm{R}^{2}$ (Kumar et al., 2008). The equation of these GO-Fm models is presented in

173 Table 3.

174 Table 1: The isotherm model equations applied in the study

2-parameter models

3-parameter models

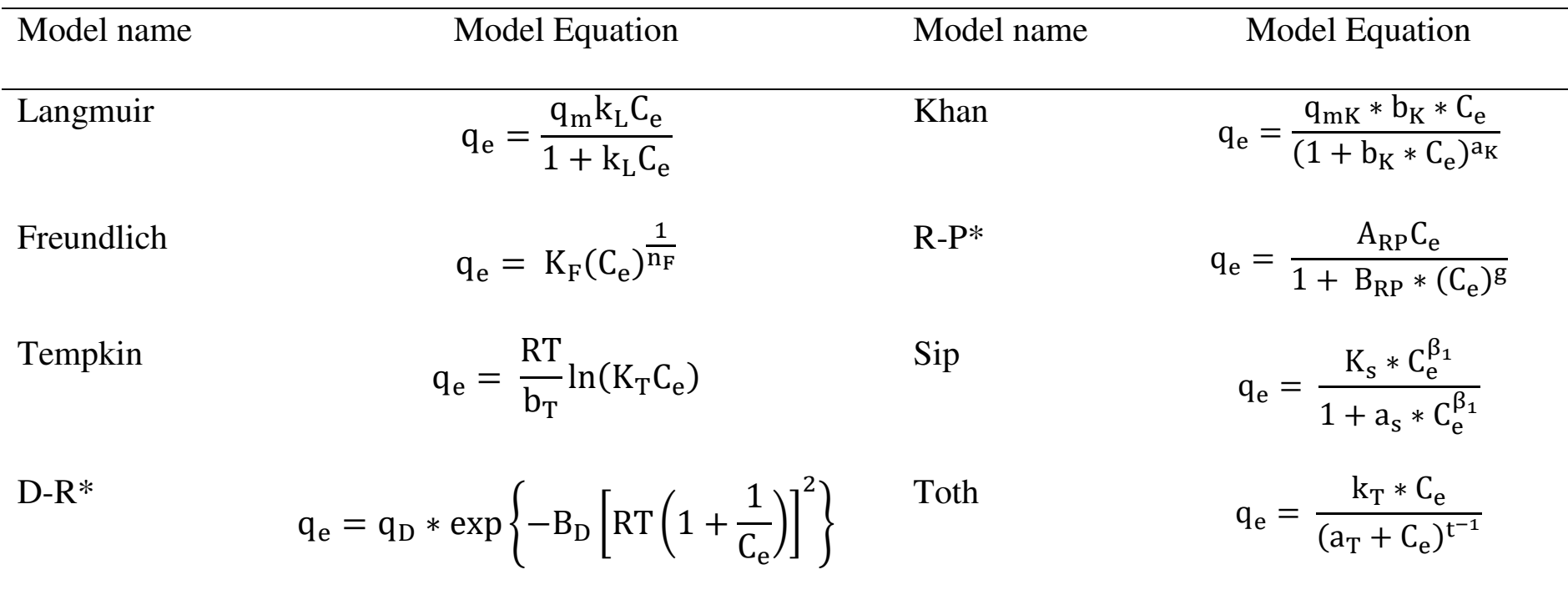

176

177

178 Table 2: The kinetic model equations applied in the study

\begin{tabular}{ll}
\hline Model name & Model equation \\
\hline Pseudo-first-order & $\mathrm{q}_{\mathrm{t}}=\mathrm{q}_{\mathrm{e}}\left[1-\exp \left(-\mathrm{k}_{1} \mathrm{t}\right)\right]$ \\
Pseudo-second-order & $\mathrm{q}_{\mathrm{t}}=\frac{\mathrm{k}_{2} * \mathrm{q}_{\mathrm{e}}^{2} * \mathrm{t}}{\left(1+\mathrm{k}_{2} * \mathrm{t}\right)}$ \\
Bangham & $\mathrm{q}_{\mathrm{t}}=\mathrm{q}_{\mathrm{e}}\left[1-\exp \left(-\mathrm{k}_{\mathrm{b}} \mathrm{t}^{\mathrm{n}}\right)\right]$ \\
Elovich & $\mathrm{q}_{\mathrm{t}}=\beta * \operatorname{In}(\alpha \beta \mathrm{t})$ \\
Intraparticle diffusion & $\mathrm{q}_{\mathrm{t}}=\mathrm{k}_{\mathrm{id}} \mathrm{t}^{0.5}$
\end{tabular}


Table 3: The applied goodness-of-fit models

\section{Error Function}

Average Relative Error (ARE)

Average Percentage Error (APE)

Sum Squares Error (ERRSQ/SSE)

Hybrid Fraction Error Function (Hybrid)

Marquardt's Percent Standard Deviation

(MPSD)

Nonlinear chi-square test $\left(\chi^{2}\right)$

Coefficient of determination $\left(\mathrm{R}^{2}\right)$
Equation

$$
\text { ARE }=\sum_{i=1}^{n}\left|\frac{\left(q_{e}\right)_{\text {exp. }}-\left(q_{e}\right)_{\text {calc. }}}{\left(q_{e}\right)_{\text {exp. }}}\right|
$$

$$
A P E \%=\frac{\sum_{i=1}^{N}\left[\left[\left(\left(q_{e}\right)_{\text {exp. }}-\left(q_{e}\right)_{\text {calc. }}\right) / q_{\text {exp. }}\right] \mid\right.}{N} x 100
$$

$$
E R R S Q=\sum_{i=1}^{n}\left[\left(q_{e}\right)_{\text {calc. }}-\left(q_{e}\right)_{\text {exp. }}\right]^{2}
$$

$$
\text { Hybrid }=\frac{100}{n-p} \sum_{i=1}^{n}\left[\frac{\left(\left(q_{e}\right)_{\text {exp. }}-\left(q_{e}\right) \text { calc. }\right)^{2}}{\left(q_{e}\right)_{\text {exp. }}}\right]_{i}
$$

$$
M P S D=\left(\sqrt[100]{\frac{1}{n-p} \sum_{i=1}^{n}\left[\frac{\left(\left(q_{e}\right)_{\text {exp. }}-\left(q_{e}\right)_{\text {calc. }}\right)}{\left(q_{e}\right)_{\text {exp. }}}\right.}\right]^{2}
$$

$$
\chi^{2}=\sum \frac{\left(q_{e . \exp }-q_{\text {e.theoretical }}\right)^{2}}{q_{\text {e.theoretical }}}
$$

$$
R^{2}=\frac{\sum_{i=1}^{n}\left(q_{e, \text { calc }}-\overline{q_{e, \mathrm{xxp}}}\right)^{2}}{\sum_{i=1}^{n}\left(q_{e, \text { calc }}-\overline{q_{e, \mathrm{exp}}}\right)^{2}+\sum_{i=1}^{n}\left(q_{e, \text { alc }}-q_{e, \mathrm{exp}}\right)^{2}}
$$

\section{Results and discussion}

185 3.1. Reaction mechanisms involved during adsorbent synthesis

The novel adsorbent (' $M A$ ') was synthesized following the procedure presented in section $\mathbf{2 . 2}$ and the reaction mechanism involved during the synthesis process is elucidated herein. The heat treatment involved during the oven-drying of the succinic acid impregnated Alhagi Graecorum powdered $(A G)$ catalysed the direct carbonylation of the succinic acid to its corresponding anhydride according to Eq. (4). The acid anhydride groups further reacted with the hydroxyl groups of ' $A G$ ' $(\mathrm{Cell}-\mathrm{OH})$ via partial or complete esterification to produce mono- 
<smiles>O=C(O)CCC(=O)O</smiles>

[Succinic acid]

197<smiles>O=C1CCC(=O)O1</smiles>

[Succinic anhydride]

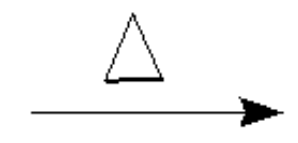

+ Cell-OH

[Alhagi cellulose]

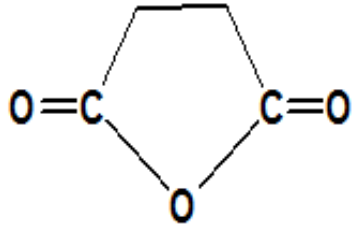

[Succinic anhydride]

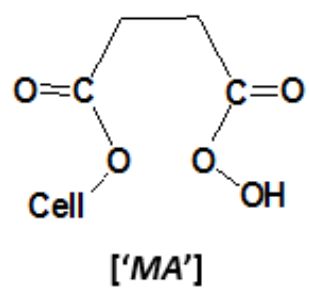

198 


\section{Effect of succinic acid concentration}

202

The variation of the succinic acid concentration and the biosorbents' carboxyl content is shown in Fig. 1 (a). The $-\mathrm{OH}$ groups of the biosorbent precursor are considered as the limiting reactant during the synthesis process. Therefore, the more readily the organic acid groups reach and interact with them, the more carboxyl group formation. This could be the reason for the observed increment in the carboxyl content on the ' $M A$ ' the succinic acid concentration initially increased (see Fig. 1a). Meanwhile, at much higher acid concentrations, the unavailability or probable exhaustion of formally available hydroxyl groups of the precursor material may cause the dissociation of already existent carboxyl groups, thus the observed carboxyl content reduction (Fig. 1a).

\section{Effect of dehydration time}

The variation of the succinic acid concentration and the biosorbents' carboxyl content is shown in Fig. 1(b). The plot depicted a sustained increment in ' $M A$ ' carboxyl content with dehydration time up to $90 \mathrm{~h}$, however, further extension of the dehydration time (beyond $90 \mathrm{~h}$ ) caused a decline. Accordingly, during the initial increase in dehydration time (from $30 \mathrm{~h}$ to $90 \mathrm{~h}$ ), there was adequate predisposal time for achieving an optimal esterification reaction between the hydroxyl groups of the cellulosic biomass and the anhydride analogue of the succinic acid. However, as the dehydration time extended beyond $90 \mathrm{~h}$, there was the exhaustion of the esterification sites, hence the observed decline in carboxyl content. 

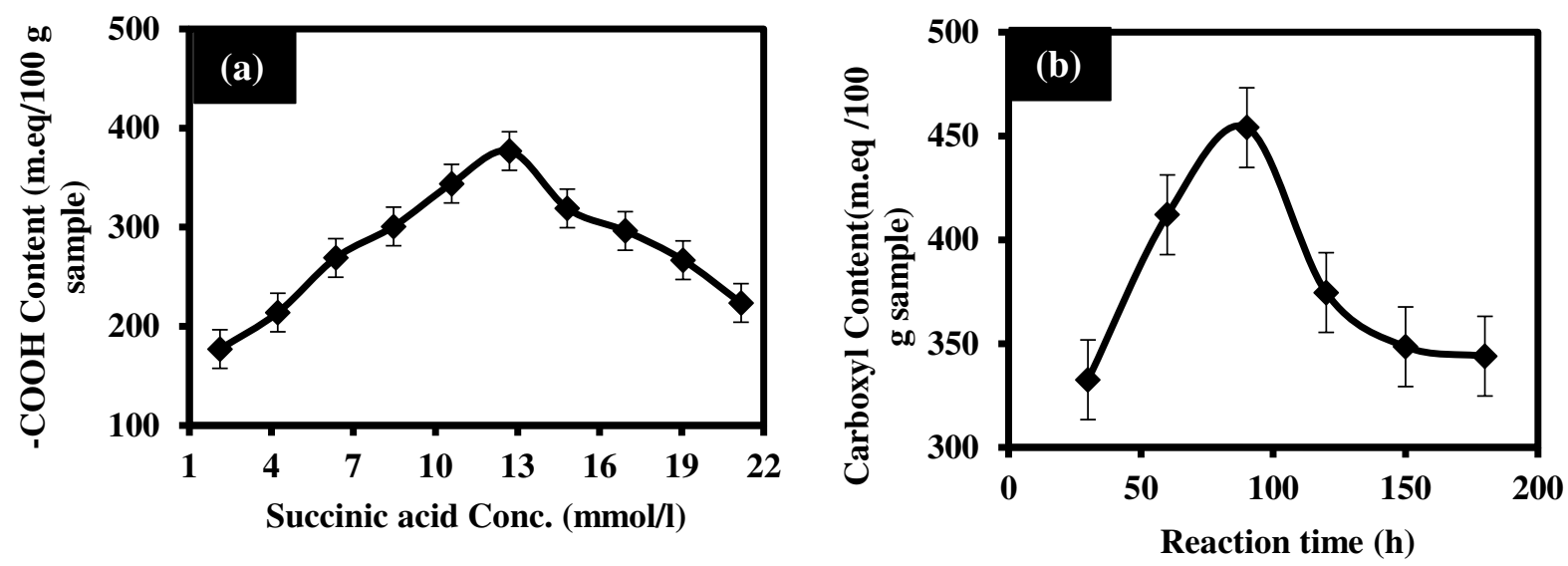

Fig. 1: The effect of (a) Succinic acid concentration and (b) dehydration time on the carboxyl content of ' $M A$ ' (error bars represent \pm standard experimental errors)

\subsection{Adsorbent characterization}

3.2.1. Fourier transform infrared spectroscopy (FTIR)

The FTIR spectra of the raw (AG), modified (MA) and metal loaded [Zn (II)-MA'] biosorbent together with their observed peaks are presented in Fig. 2. Similar peaks were observed for the biosorbent samples, except for some slight wavenumber shifts, peak broadening or shrinking etc sequel to functionalization and heavy metal loading. The prominent peaks identified at 3333 $\mathrm{cm}^{-1}, 2916 \mathrm{~cm}^{-1}, 2844 \mathrm{~cm}^{-1}$, between $1719 \& 1610 \mathrm{~cm}^{-1}$, and the one around $1512 \mathrm{~cm}^{-1}$ is assigned to the $\mathrm{O}-\mathrm{H}$ stretching vibration, symmetric $\mathrm{C}-\mathrm{H}$ stretch, asymmetric $\mathrm{C}-\mathrm{H}$ stretch, aromatic $\mathrm{C}=\mathrm{O}$ group of ester and lignin $\mathrm{C}-\mathrm{O}$ linkage, respectively (Adigun et al., 2019). The peaks domicile at 1423 and $1228 \mathrm{~cm}^{-1}$ are typical of the asymmetric - $\mathrm{COOH}$ stretch of cellulose and hemicellulose. Also, a signature bending vibration band of the $\mathrm{C}-\mathrm{O}$ group is assigned to the peak at wavenumber $1024 \mathrm{~cm}^{-1}$ (Sasmal et al., 2012). Meanwhile, the post adsorption FTIR pattern is characterized by variations in peak length and intensities (Fig. 2). 


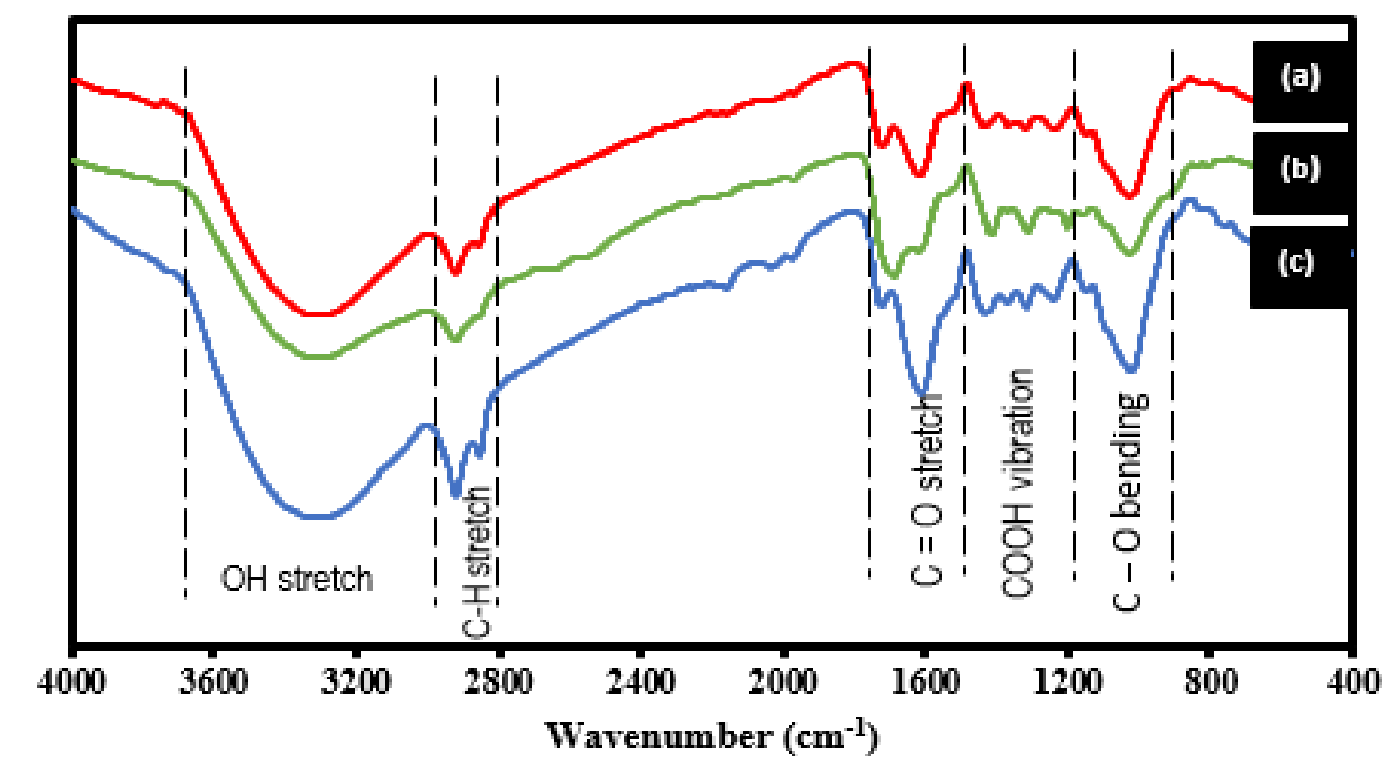

Fig. 2: FTIR spectra for (a) Zn (II) Loaded ' $M A$ ' (b) ' $M A$ ' (c) Raw Alhagi

\subsubsection{Scanning electron microscopy (SEM)}

242 The raw Alhagi (Fig. 3a) depicted a textural characteristic of thin, paper-like overlapped

243 structures, with some degree of surface roughness and poorly developed pores. After 244 undergoing the functionalization stages of acid and heat treatment, ' $M A$ ' surface significantly 245 transformed and depicted well-developed pores and increased surface roughness (Fig.3b). Upon further comparison of the pre-and-post adsorption image of MA (Figs. $\mathbf{3 b} \boldsymbol{\&} \mathbf{3 c}$ ), the only obvious identified distinction is that the surface of $\mathrm{Zn}$ (II)-loaded ' $M A$ ' depicted a characteristic lustre. This could probably be due to the presence of the adsorbed zinc ion.

The EDX elemental mapping was performed to confirming the presence of adsorbed zinc ions and also to ascertain their percentage deposition. As shown in Fig. 4, the presence of carbon (66.97\%), oxygen $(28.81 \%)$ and Zinc $(4.22 \%)$ was detected in the post adsorption ' $M A$ ' sample. This finding serves as a confirmation for the uptake of Zinc ion by ' $M A$ ' via the adsorption process. 


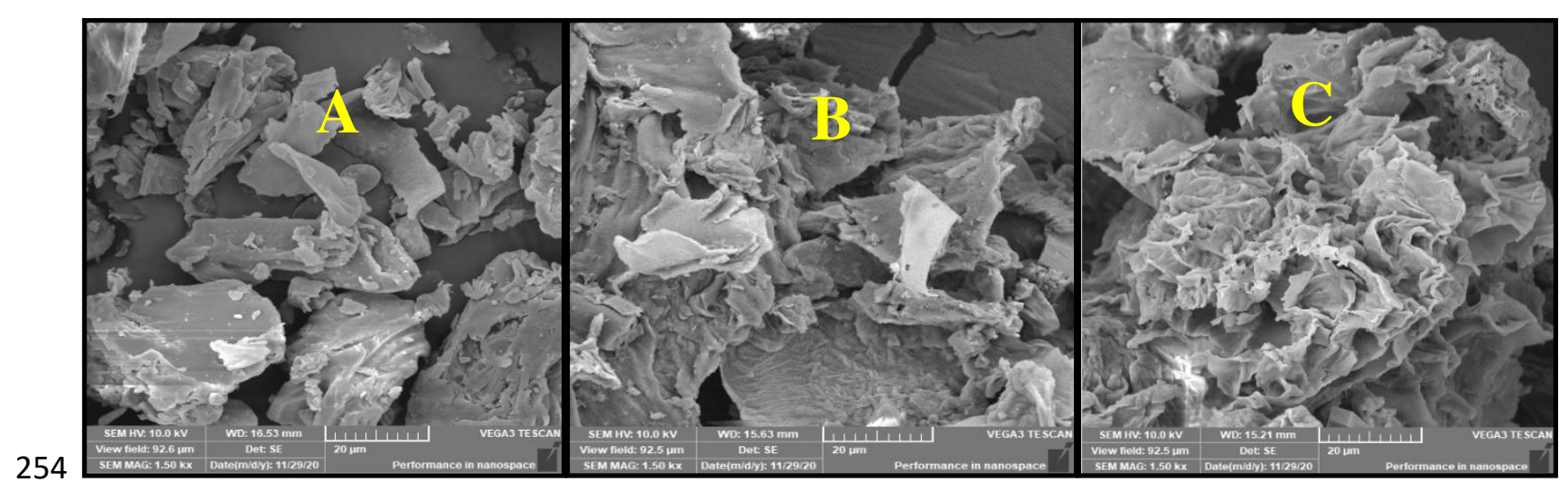

255 Fig. 3: SEM images of (a) raw Alhagi (b) ' $M A$ ' (c) Zn (II)-loaded ' $M A$ '

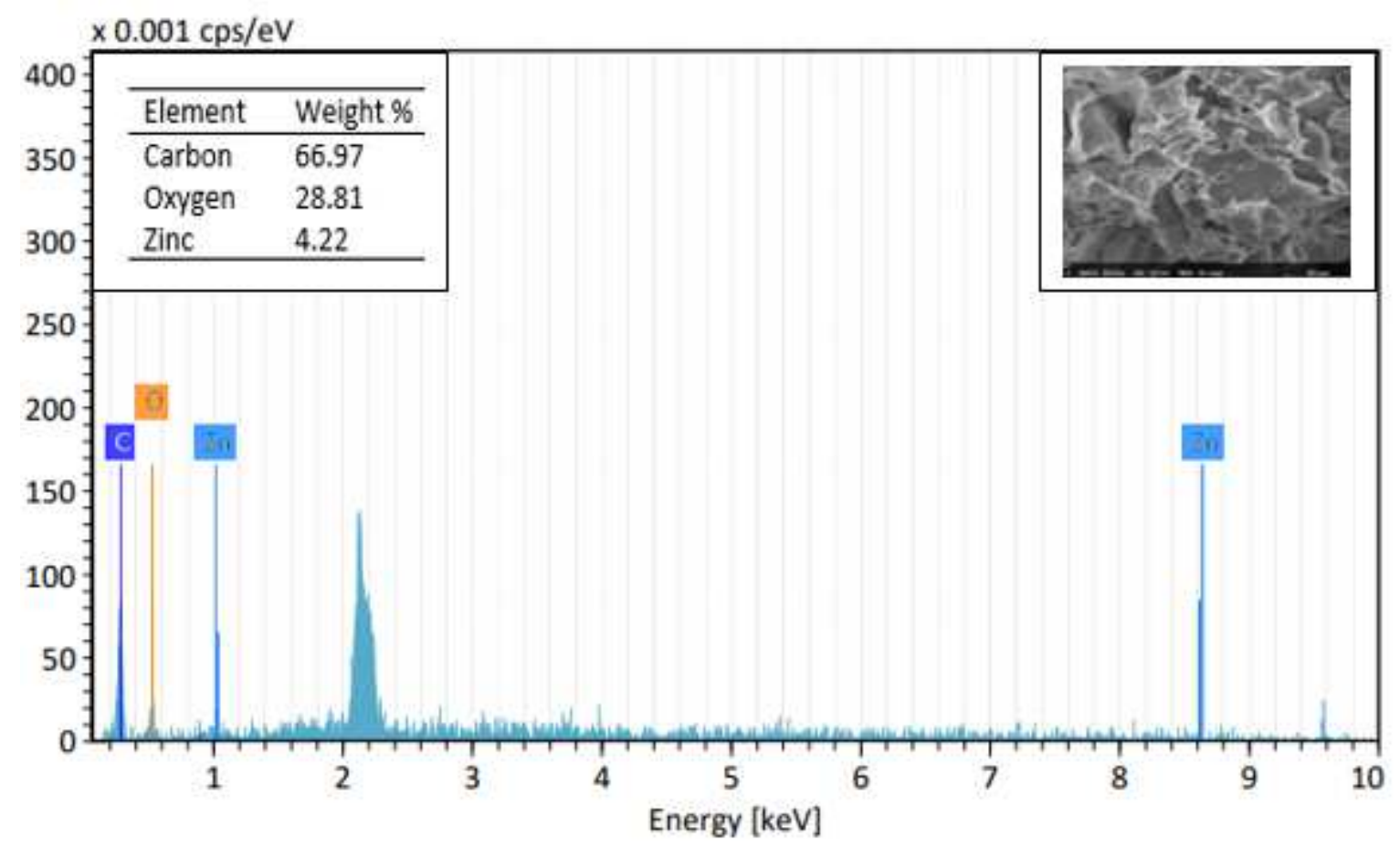

256

Fig. 4: EDX spectra for Zn (II)-loaded ' $M A$ '

258 3.3. Adsorption performance of ' $M A$ '

\subsubsection{Effect of $\mathrm{pH}$}

It has been reported that the surface charge of a given adsorbent is a function of the adsorbate

261 solution $\mathrm{pH}$ and its (biosorbents') point of zero charges, $\mathrm{pH}$ PZC. According to Fig. 5a, the ' $M A$ '

262 depicted a pHPZC of $\mathrm{pH} 4.1$, an indication of its surface acidity nature. The assertion was further 
corroborated by the presence of carboxylic functional groups identified from the FTIR spectra.

Meanwhile, Eqs. (6) and (7) presents the stoichiometric illustration of the ion exchange/electrostatic interaction mechanism occurring within the zinc ion sorption system. These equilibrium reactions are strongly dependent on the $\mathrm{pH}$ of the adsorbate solution. At strongly acidic conditions $(\mathrm{pH}<\mathrm{pH}$ PZC) the backward reaction of Eq (6) is favoured, thus the predominance of the carboxylic groups on the adsorbent in its non-ionized form. A typical scenario was observed at $\mathrm{pH} 2.0$ (Figure 5b), where no notable adsorption capacity value was recorded, due to a strong electrostatic repulsion between the zinc cations and protonated adsorbent surfaces.

$2 \mathrm{MA}-\mathrm{COOH}(\mathrm{s}) \quad \longleftrightarrow 2 \mathrm{MA}^{-\mathrm{COO}^{-}}{ }_{(\mathrm{aq})}+2 \mathrm{H}^{+}{ }_{(\mathrm{aq})}$

$$
2 M A-\mathrm{COO}^{-}(\mathrm{s})+\mathrm{Zn}^{2+}{ }_{(\mathrm{aq})} \quad \longleftrightarrow \quad(M A-\mathrm{COO})_{2} \mathrm{Zn}_{(\mathrm{s})}
$$

Subsequent deprotonation of the adsorption sites as shown in Eq. (7) due to a decrease in the acidity of the adsorption system $(\mathrm{pH}>\mathrm{pHpzc})$ greatly improved the adsorbents' adsorption capacity. For instance, the adsorption capacity was raised from 0 to $18.34 \mathrm{mg} / \mathrm{g}$ just by a single unit increase in the solution $\mathrm{pH}$ (from $\mathrm{pH} 2.0$ to $\mathrm{pH} 3.0$ ). Subsequent and progressive single unit-wise increase in the solution $\mathrm{pH}$ close to and beyond the pHpzc always resulted in more than $50 \%$ improvement in the adsorption capacity until the attainment of a maximum at $\mathrm{pH}$ 6.0 (optimum $\mathrm{pH}$ for the study). Notably, the $\mathrm{pH}$ variation studies were terminated at $\mathrm{pH} 6.0$, as the author had initially recorded insignificant adsorption at alkaline $\mathrm{pH}$ regions due to possible precipitation of the zinc cation to its hydroxide analogue. 


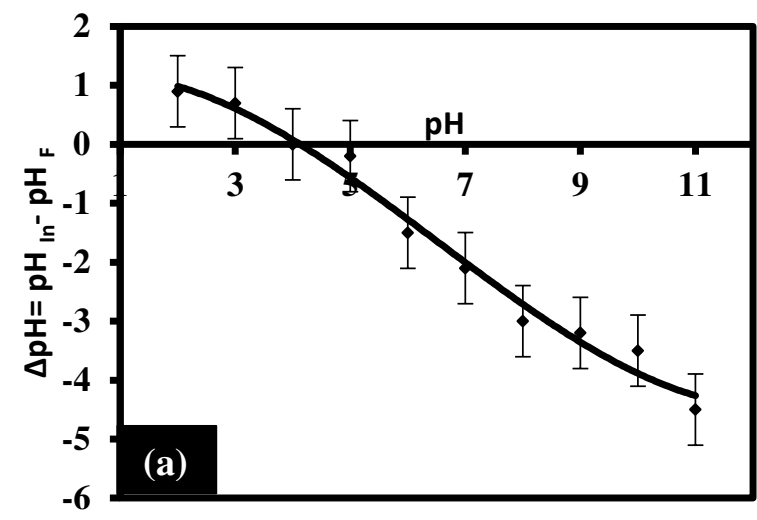

284

285

286

287

288

289

290

291

292

293

294

295

296

297

298

299

300

301

302

\subsubsection{Effect of adsorbent dosage}

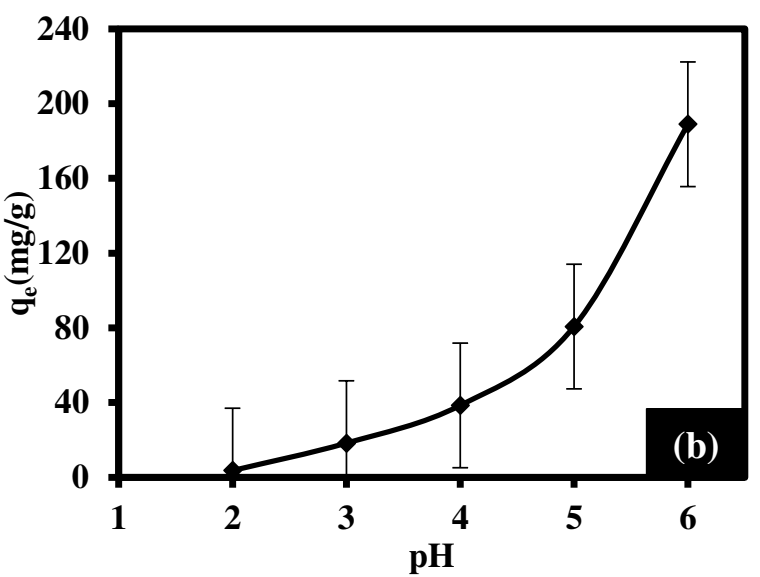

pH

Fig. 5: Plot of the (a) $\mathrm{pH}$ of point of zero charge (b) effect of $\mathrm{pH}$ on the adsorption capacity (error bars represent \pm standard experimental errors)

The variation in the adsorption capacity $(\mathrm{mg} / \mathrm{g})$ and removal efficiency $(\%)$ of ' $M A$ ' due to the amount of adsorbent used (dosage, g/L) was simultaneously investigated. According to the result presented in Figure 6a, the adsorption capacity was found to vary inversely as the removal efficiency. Meanwhile, Igwegbe, Oba, et al. (2020) has reported the strong dependence of removal efficiency on the adsorbates' initial concentration, hence, their values may not provide an accurate reflection of the sorption ability of a given adsorbent. Therefore, our discussion here only emphasized the relationship between that adsorbent dosage and adsorption capacity (which provides a better reflection of the adsorbents' intrinsic adequacy) (Aniagor et al., 2021; Igwegbe, Oba, et al., 2020; Oba et al., 2021).

Figure 6a generally depicted a steady decline in the adsorption capacity as the adsorbent dosage increased from 0.3 to $7.0 \mathrm{~g} / \mathrm{L}$. Although a general decline in the adsorption capacity was observed as the adsorbent dosage increased, however, the extent of adsorption capacity decline is particularly dependent on the adsorbent mass ratio at a given time. For instance, a $0.2 \mathrm{~g} / \mathrm{L}$ increased in the adsorbent dosage (that is from 0.3 to $0.5 \mathrm{~g} / \mathrm{L}$ ) resulted in about a $12 \%$ loss of 
adsorption capacity, while a $0.5 \mathrm{~g} / \mathrm{L}$ increase (that is from 0.5 to $1.0 \mathrm{~g} / \mathrm{L}$ ) showed about $35 \%$ adsorption capacity loss. A similar observation which is related to the progressive saturation and eventual clogging of the adsorption sites, thus limiting zinc ions adsorption, were made at higher adsorbent dosages (Hashem, ANIAGOR, Nasr, et al., 2021; Hashem, Badawy, et al., 2020). Hence, the maximum adsorption capacity for the study was recorded at $0.3 \mathrm{~g} / \mathrm{L}$ adsorbent dosage.

\subsubsection{Effect of adsorption time}

Figure $6 \mathrm{~b}$ presents the combined plot of contact time and initial concentration effect on the adsorption capacity. The amount adsorbed generally improved as the adsorption time extended and as the initial adsorbate concentration increased. Meanwhile, a rapid uptake was witnessed within the first 10 min of adsorption, as the respective amount of zinc ion adsorbed was strongly dependent on the initial adsorbate concentration. Within this initial adsorption stage (first 10 min), about $80 \%$ of the optimum adsorption capacity for the study was realized. This occurrence could be due to the huge availability of active sites and the high solute (zinc ion) concentration gradient which offered a substantial driving force for favourable uptake (Zhuang et al., 2019; Zhuang et al., 2020). As the adsorption time extended (beyond $10 \mathrm{~min}$ ), the solute uptake amounts progressively diminished until the attainment of equilibrium at $120 \mathrm{~min}$. The adsorption capacity reduction as contact time extended is due to the progressive saturation of the adsorption sites, thus limiting the uptake of more solutes (Guo et al., 2019). Similar equilibrium time as that obtained in this study has been previously reported by other authors that employed cellulose-based adsorbent in the uptake of different metal cations (Ebrahimi et al., 2015; Hashem, Badawy, et al., 2020; Hashem, Fletcher, et al., 2020). 

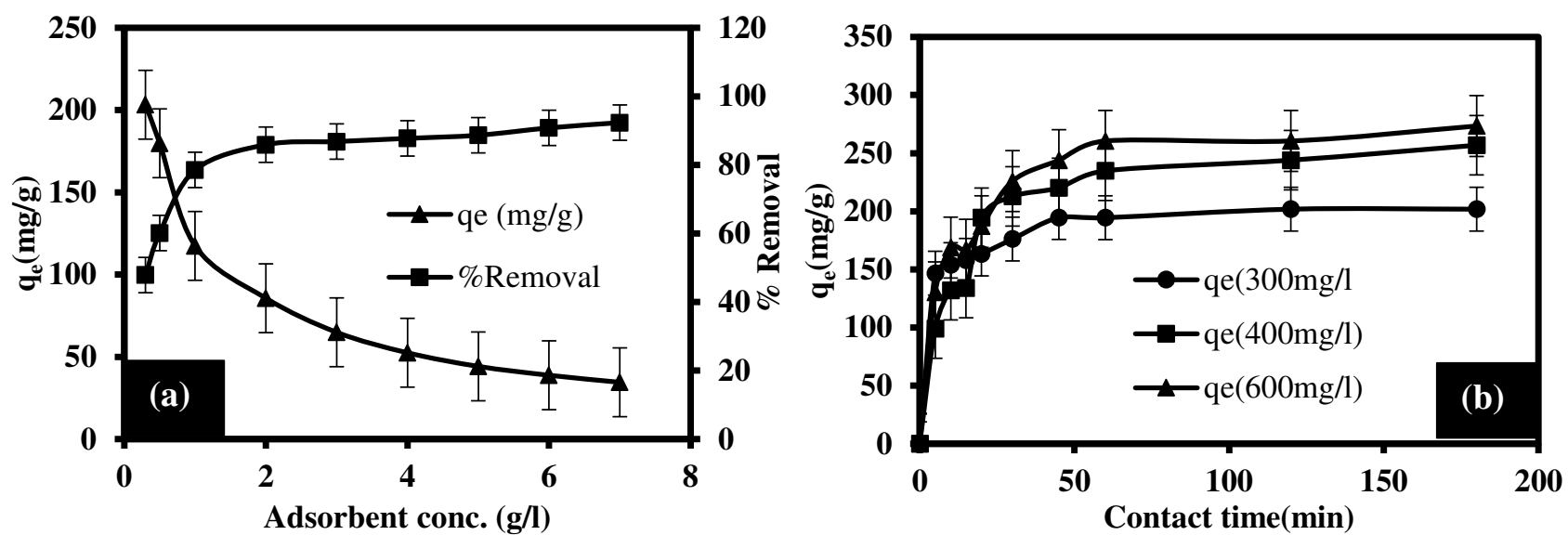

Adsorbent conc. (g/l)

Fig. 6: (a) Combined effect of adsorbent dose on adsorption capacity and removal efficiency (b) effect of contact time on the adsorption capacity at varying initial adsorbate concentration (error bars represent \pm standard experimental errors)

\subsection{Adsorption modelling}

\subsubsection{Isotherm studies}

The adsorbate concentration effect of the equilibrium adsorption data was fitted to different isotherm models whose equations are depicted in Table 1. The evaluated model parameters and their $\mathrm{R}^{2}$-values are presented in Table 4, while the experimental dataset was presented as a plot in Fig. 7. Meanwhile, the insufficiency of the application $\mathrm{R}^{2}$-value alone for the determination of the best fit nonlinear model has been highlighted (Abonyi et al., 2019). As a result, seven (7) error model, whose equations are presented in Table $\mathbf{3}$ were applied for determining the best-fit isotherm model. To limit the inconsistencies often experienced during the application of multiple error model (as was the case in this study), a process of normalizing the different error values from the error models for a given isotherm was adopted. Consequently, only the sum of normalized error (SNE) value will be considered during the isotherm modelling discussion and the lower the SNE value (as shown in Table 5), the better the model fit to the experimental isotherm data. The error values and the corresponding SNE for all the isotherm models are depicted in Table 5. 
The Sips model is considered the overall best fit since it returned the lowest SNE value of 1.0498 and an appreciably high $\mathrm{R}^{2}$-value. As a hybrid model, Sip isotherm bridges between the homogenous monolayer and heterogeneous multilayer postulations of the Langmuir and Freundlich model, respectively. At low adsorbate concentration, the Sip model tilt towards the Freundlich model and conversely favour the Langmuir model at high concentration. The Freundlich constant 'n' (adsorbate-adsorbent affinity index) value which is greater than unity indicates favourable adsorption (Liu et al., 2018), which occurred mostly at low adsorbate concentration.

The magnitude of the D-R mean energy $(\mathrm{E}, \mathrm{KJ} / \mathrm{mol})$ is often applied for classifying the nature of a given adsorption system (Hashem, Aniagor, Hussein, et al., 2021). The physical and chemical nature of an adsorption system is respectively implied at $\mathrm{E}<8 \mathrm{KJ} / \mathrm{mol}$ and $\mathrm{E}>8$ $\mathrm{KJ} / \mathrm{mol}$ (Dada et al., 2012). By applying Eq. (8), a D-R mean energy value of $0.382 \mathrm{KJ} / \mathrm{mol}$ (E $<8 \mathrm{KJ} / \mathrm{mol}$ ) was obtained in the study. Hence, the occurrence of physical adsorption, with electrostatic interaction between the adsorbate and adsorbent, which was further confirmed in section 3.7, is thus postulated (Wang et al., 2013).

$359 \quad E=\frac{1}{\sqrt{2 \beta_{D}}}$

The Langmuir model also showed a maximum adsorption capacity of $229.985 \mathrm{mg} / \mathrm{g}$ and sa favourability index $\left(\mathrm{R}_{\mathrm{L}}\right)$ of $7.0 \mathrm{E}-03$, which is indicative of a favourable adsorption process. The positive Temkin isotherm constant $\left(\mathrm{b}_{\mathrm{T}}\right)$ recorded in the study implies a favourable sorption process. Furthermore, the heterogeneity of the Zinc adsorption system was further confirmed by the Redlich-Peterson g-values of 0.195 , which is approaching zero. Judging from the SNE values, the best-fitted adsorption isotherm models in their descending order is Sips > Toth > Redlich-Peterson $>$ Khan $>$ Freundlich $>$ Temkin $>$ Langmuir $>$ Dubinin-Radushkevich . 
368 Table 4: Isotherm model parameters

2-parameter models

\begin{tabular}{llll}
\hline Langmuir & Freundlich & Temkin & D-R* \\
\hline $\mathrm{q}_{\max }=229.985$ & $\mathrm{n}_{\mathrm{F}}=3.109$ & $\mathrm{~A}_{\mathrm{T}}=7.6 \mathrm{E}-02$ & $\mathrm{q}_{\mathrm{o}}=182.656$ \\
$\mathrm{~K}_{\mathrm{L}}=1.6134$ & $\mathrm{~K}_{\mathrm{F}}=23.371$ & $\mathrm{~b}_{\mathrm{T}}=52.219$ & $\mathrm{~B}_{0}=1.3 \mathrm{E}-03$ \\
$\mathrm{R}_{\mathrm{L}}=7.0 \mathrm{E}-03$ & $\mathrm{R}^{2}=0.983$ & $\mathrm{R}^{2}=0.987$ & $\mathrm{R}^{2}=0.993$ \\
$\mathrm{R}^{2}=0.990$ & & & \\
\hline
\end{tabular}

3-parameter models

\begin{tabular}{llll}
\hline Khan & R-P* & Sips & Toth \\
\hline $\mathrm{q}_{\max }=2.125$ & $\mathrm{k}_{\mathrm{g}}=29.109$ & $\mathrm{~K}_{\mathrm{S}}=4.970$ & $\mathrm{k}_{\mathrm{T}}=13.592$ \\
$\mathrm{~b}_{\mathrm{K}}=303.079$ & $\alpha_{\mathrm{R}}=-0.127$ & $\alpha_{\mathrm{S}}=6.1 \mathrm{E}-03$ & $\alpha_{\mathrm{T}}=9.0 \mathrm{E}-02$ \\
$\alpha_{\mathrm{K}}=0.633$ & $\mathrm{~g}=0.195$ & $\beta_{\mathrm{S}}=0.600$ & $1 / \mathrm{t}=0.588$ \\
$\mathrm{R}^{2}=0.982$ & $\mathrm{R}^{2}=0.981$ & $\mathrm{R}^{2}=0.971$ & $\mathrm{R}^{2}=0.981$
\end{tabular}


371 Table 5: Error-values for isotherm modelling

2-parameter models

\begin{tabular}{|c|c|c|c|}
\hline Langmuir & Freundlich & Temkin & D-R* \\
\hline ARE $=0.988$ & $\mathrm{ARE}=1.269$ & $\mathrm{ARE}=1.107$ & $\mathrm{ARE}=0.568$ \\
\hline $\mathrm{APE}=10.976$ & $\mathrm{APE}=14.104$ & $\mathrm{APE}=12.304$ & $\mathrm{APE}=6.309$ \\
\hline $\mathrm{EABS}=114.377$ & $\mathrm{EABS}=145.447$ & $\mathrm{EABS}=129.053$ & $\mathrm{EABS}=82.404$ \\
\hline ERRSQ $=2360.033$ & ERRSQ $=3706.172$ & ERRSQ $=2846.789$ & ERRSQ $=1541.017$ \\
\hline Hybrid $=21.817$ & Hybrid $=36.821$ & Hybrid $=26.851$ & Hybrid $=11.103$ \\
\hline MPSD $=0.253$ & MPSD $=0.464$ & MPSD $=0.321$ & MPSD $=0.082$ \\
\hline $\mathrm{X}^{2}=17.735$ & $X^{2}=28.374$ & $X^{2}=0.21 .607$ & $X^{2}=9.552$ \\
\hline SNE $=1.0704$ & $\mathrm{SNE}=1.0611$ & $\mathrm{SNE}=1.0672$ & $\mathrm{SNE}=1.0714$ \\
\hline \multicolumn{4}{|c|}{ 3-parameter models } \\
\hline Khan & R-P* & Sips & Toth \\
\hline $\mathrm{ARE}=1.211$ & $\mathrm{ARE}=1.319$ & $\mathrm{ARE}=1.300$ & $\mathrm{ARE}=1.267$ \\
\hline $\mathrm{APE}=13.452$ & $\mathrm{APE}=14.653$ & $\mathrm{APE}=14.443$ & $\mathrm{APE}=14.081$ \\
\hline EABS $=150.677$ & $\mathrm{EABS}=151.446$ & $\mathrm{EABS}=193.301$ & $\mathrm{EABS}=167.086$ \\
\hline ERRSQ $=3734.883$ & ERRSQ $=4047.317$ & ERRSQ = 5864.111 & ERRSQ $=4377.627$ \\
\hline Hybrid $=30.715$ & Hybrid $=40.132$ & Hybrid $=37.165$ & Hybrid $=32.363$ \\
\hline MPSD $=0.325$ & MPSD $=0.506$ & MPSD $=0.245$ & MPSD $=0.299$ \\
\hline$X^{2}=27.857$ & $X^{2}=30.868$ & $X^{2}=45.670$ & $X^{2}=29.358$ \\
\hline SNE $=1.0600$ & $\mathrm{SNE}=1.0590$ & $\mathrm{SNE}=1.0498$ & $\mathrm{SNE}=1.0558$ \\
\hline
\end{tabular}




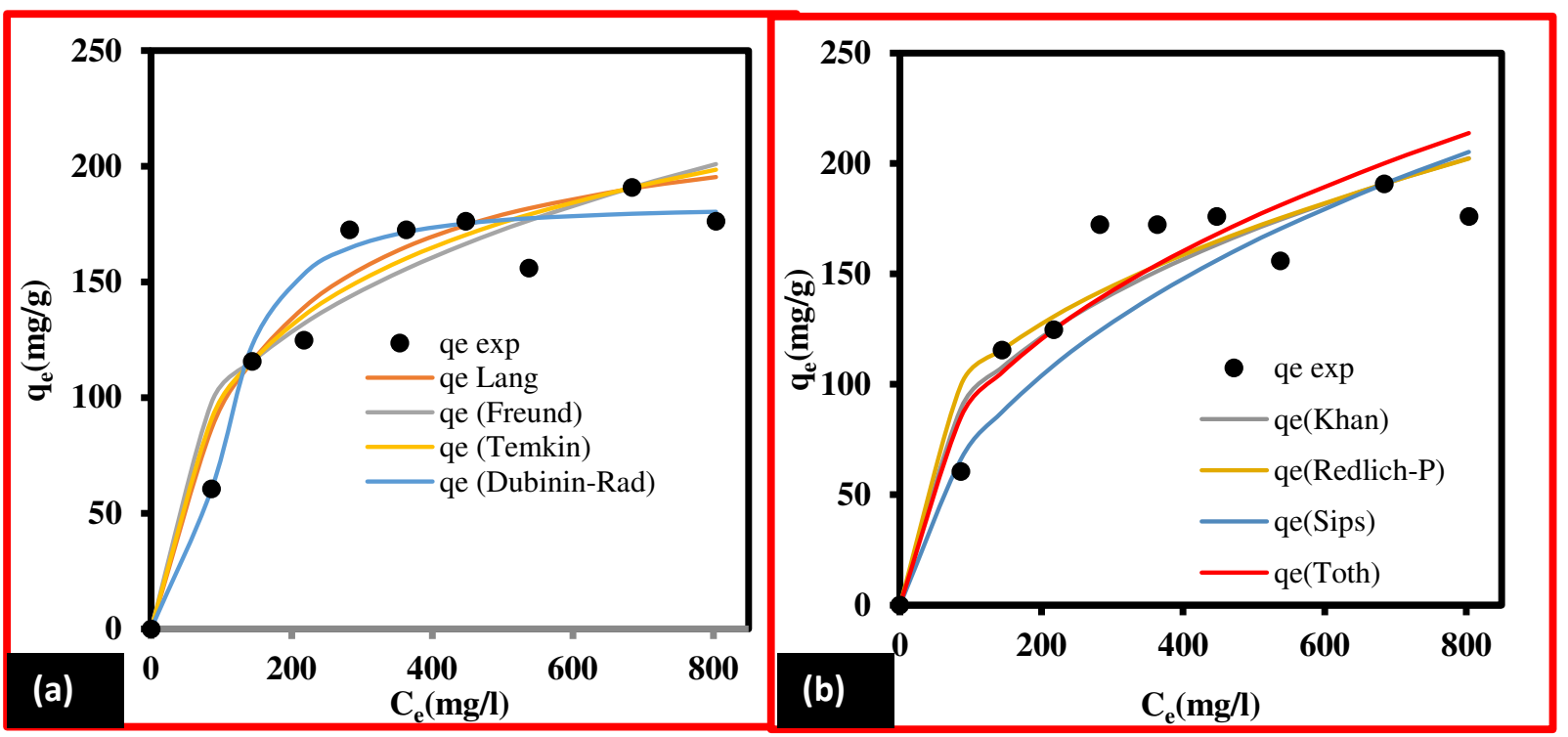

Fig. 7: The isotherm plot for (a) 2-parameter models (b) 3-parameter model

As already explained in section 3.4.1, only the sum of normalized error (SNE) value will be considered in the discussions on kinetic studies and the lower the SNE value (as shown in

Table 6), the better the kinetic model fit. The error values and the corresponding SNE values for all the kinetic models are depicted in Table 6. The Elovich (SNE = 1.0429), intraparticle diffusion $(\mathrm{SNE}=1.0205)$ and pseudo-first-order $(\mathrm{SNE}=1.0455)$ provided the best fitting for 200, 400 and $600 \mathrm{mg} / \mathrm{L}$ adsorption system, respectively. Similarly, the plot of the different kinetic models is presented in Fig. 8.

Despite the emergence of the respective best fit models, the relatively low SNE value ( $\leq$ 1.0872) and high $\mathrm{R}^{2}$-values ( $\left.\geq 0.92\right)$ recorded for all models applied in modelling of the entire adsorption system (200, 400 and $600 \mathrm{mg} / \mathrm{L})$ shows their good fitting to the experimental dataset. Studies (Delgado et al., 2019; Wang et al., 2020) have shown that PFO usually provides a better fit at high initial adsorbate concentration, where the ratio of adsorbate ions is higher compared to the available active sites. This assertion supports the emergence of PFO as the best fit model for the $600 \mathrm{mg} / \mathrm{L}$ adsorption system. Meanwhile, the linear dependence of its 
rate constant $\left(\mathrm{k}_{1}\right)$ on the initial Zn (II) ion concentration has been highlighted (Wang et al., 391 2020). The values of adsorption rate constant recorded for the PFO model (which ranges from 0.0683 to 0.155 ) (Table 7) was in all cases greater than those obtained for PSO; thus, 393 emphasizing the superiority of PFO model prediction to that of PSO in this study. Elovich 394 model postulates the heterogeneity of an adsorbents' surface and a direct variation between the 395 adsorption duration and activation energy (Aniagor et al., 2019). The model also depicted a 396 low desorption constant $(\beta)$ value in the range of $0.020-0.024$ (Table 7), which implies 397 improved zinc ion sorption onto ' $M A$ ' for all adsorption systems. Notably, the value of 398 intraparticle (c-value) recorded for the $400 \mathrm{mg} / \mathrm{L}$ system was extraordinarily low (0.01) and it 399 implies a negligible boundary layer effect within such a system. Conversely, the occurrence of 400 greater boundary layer effects was observed for 200 and $600 \mathrm{mg} / \mathrm{L}$ adsorption system, as 401 informed by their large c-values of 134.767 and 131.564, respectively (Table 7). 
403 Table 6: Error-values for kinetic modelling

\begin{tabular}{|c|c|c|c|c|}
\hline Pseudo-first order & Pseudo-second order & Elovich & Bangham & Intra-particle diffusion \\
\hline \multicolumn{5}{|l|}{$200 \mathrm{mg} / \mathrm{L}$} \\
\hline $\mathrm{ARE}=0.717$ & $\mathrm{ARE}=0.381$ & $\mathrm{ARE}=0.991$ & $\mathrm{ARE}=0.224$ & $\mathrm{ARE}=0.302$ \\
\hline $\mathrm{APE}=7.966$ & $\mathrm{APE}=4.244$ & $\mathrm{APE}=11.013$ & $\mathrm{APE}=2.493$ & $\mathrm{APE}=3.357$ \\
\hline EABS $=115.729$ & $\mathrm{EABS}=60.948$ & $\mathrm{EABS}=172.162$ & $\mathrm{EABS}=39.338$ & $\mathrm{EABS}=57.578$ \\
\hline ERRSQ = 3006.291 & ERRSQ = 915.453 & ERRSQ $=5968.522$ & ERRSQ $=269.545$ & ERRSQ = 798.796 \\
\hline Hybrid $=19.433$ & Hybrid $=5.959$ & Hybrid $=34.194$ & Hybrid $=1.526$ & Hybrid $=4.103$ \\
\hline MPSD $=0.126$ & MPSD $=0.039$ & MPSD $=0.201$ & MPSD $=0.009$ & $\mathrm{MPSD}=0.021$ \\
\hline$X^{2}=23.164$ & $X^{2}=6.540$ & $X^{2}=37.727$ & $X^{2}=1.580$ & $X^{2}=4.290$ \\
\hline $\mathrm{SNE}=\mathbf{1 . 0 5 5 6}$ & $\mathrm{SNE}=\mathbf{1 . 0 8 5 3}$ & $\mathrm{SNE}=1.0429$ & $\mathrm{SNE}=1.1676$ & $\mathrm{SNE}=\mathbf{1 . 0 8 7 2}$ \\
\hline \multicolumn{5}{|l|}{$400 \mathrm{mg} / \mathrm{L}$} \\
\hline $\mathrm{ARE}=0.640$ & $\mathrm{ARE}=0.478$ & $\mathrm{ARE}=0.641$ & $\mathrm{ARE}=0.418$ & $\mathrm{ARE}=2.256$ \\
\hline $\mathrm{APE}=7.117$ & $\mathrm{APE}=5.322$ & $\mathrm{APE}=7.118$ & $\mathrm{APE}=4.648$ & $\mathrm{APE}=25.072$ \\
\hline $\mathrm{EABS}=98.498$ & $\mathrm{EABS}=72.640$ & $\mathrm{EABS}=128.429$ & $\mathrm{EABS}=69.708$ & $\mathrm{EABS}=444.425$ \\
\hline ERRSQ = 2094.604 & ERRSQ = 1534.557 & ERRSQ $=2758.988$ & ERRSQ = 1206.422 & ERRSQ = 38727.5 \\
\hline Hybrid $=14.619$ & Hybrid $=11.040$ & Hybrid $=13.857$ & Hybrid $=7.874$ & Hybrid $=170.500$ \\
\hline MPSD $=0.111$ & MPSD $=0.081$ & MPSD $=0.072$ & MPSD $=0.053$ & MPSD $=0.807$ \\
\hline$X^{2}=14.079$ & $X^{2}=9.0132$ & $X^{2}=15.143$ & $X^{2}=7.045$ & $X^{2}=149.164$ \\
\hline $\mathrm{SNE}=1.0645$ & $\mathrm{SNE}=1.0642$ & $\mathrm{SNE}=1.0599$ & $\mathrm{SNE}=1.0744$ & $\mathrm{SNE}=1.0205$ \\
\hline \multicolumn{5}{|l|}{$600 \mathrm{mg} / \mathrm{L}$} \\
\hline $\mathrm{ARE}=0.781$ & $\mathrm{ARE}=0.466$ & $\mathrm{ARE}=0.614$ & $\mathrm{ARE}=0.308$ & $\mathrm{ARE}=0.763$ \\
\hline $\mathrm{APE}=8.676$ & $\mathrm{APE}=5.174$ & $\mathrm{APE}=6.824$ & $\mathrm{APE}=3.422$ & $\mathrm{APE}=8.473$ \\
\hline $\mathrm{EABS}=124.270$ & $\mathrm{EABS}=81.743$ & $\mathrm{EABS}=131.238$ & $\mathrm{EABS}=59.301$ & $\mathrm{EABS}=158.100$ \\
\hline ERRSQ $=4855.067$ & ERRSQ = 1347.187 & $E R R S Q=2375.086$ & ERRSQ = 1003.834 & $E R R S Q=4581.149$ \\
\hline Hybrid $=33.572$ & Hybrid $=7.952$ & Hybrid $=10.656$ & Hybrid $=5.527$ & Hybrid $=21.520$ \\
\hline $\mathrm{MPSD}=0.238$ & $\mathrm{MPSD}=0.048$ & MPSD $=0.0512$ & MPSD $=0.0309$ & MPSD $=0.110$ \\
\hline$X^{2}=53.369$ & $X^{2}=7.561$ & $X^{2}=11.003$ & $X^{2}=4.968$ & $X^{2}=22.673$ \\
\hline $\mathrm{SNE}=\mathbf{1 . 0 4 5 5}$ & $\mathrm{SNE}=1.0764$ & $\mathrm{SNE}=1.0675$ & $\mathrm{SNE}=1.0733$ & $\mathrm{SNE}=1.0462$ \\
\hline
\end{tabular}




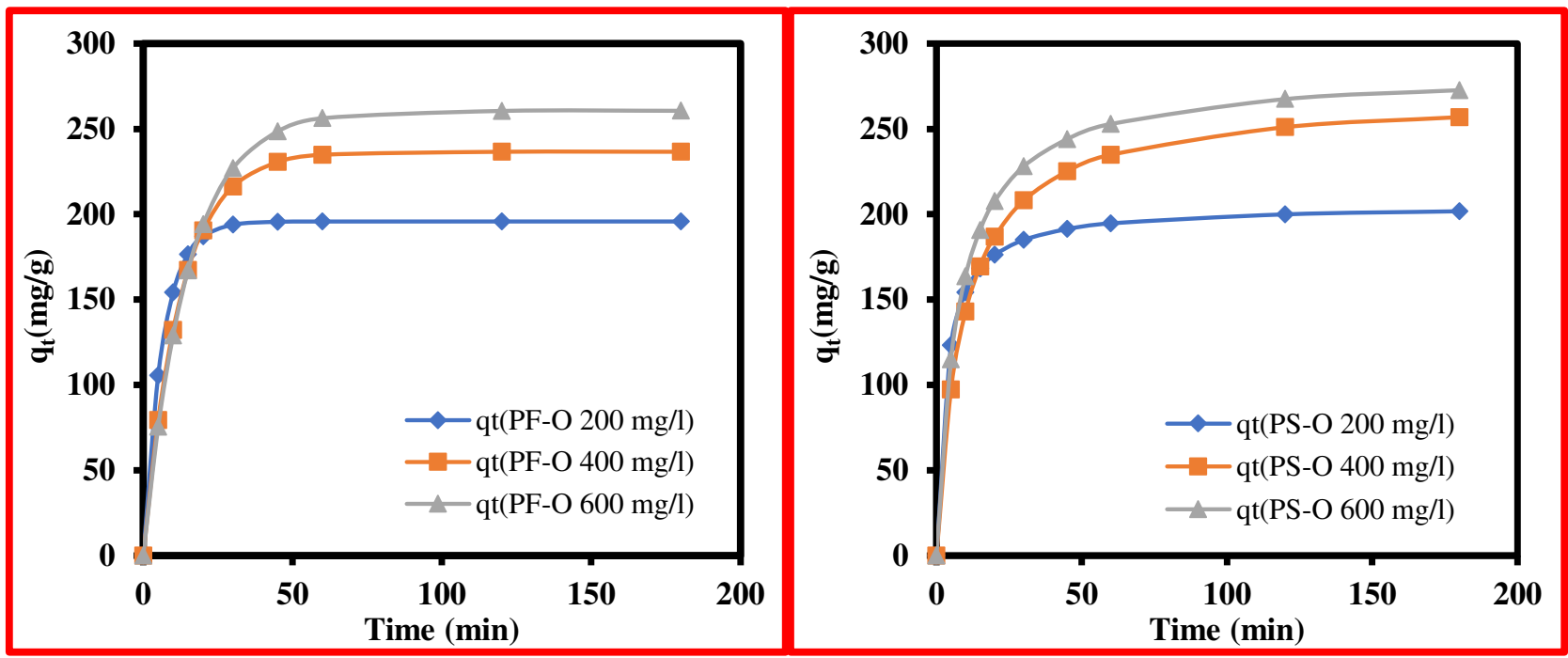

407
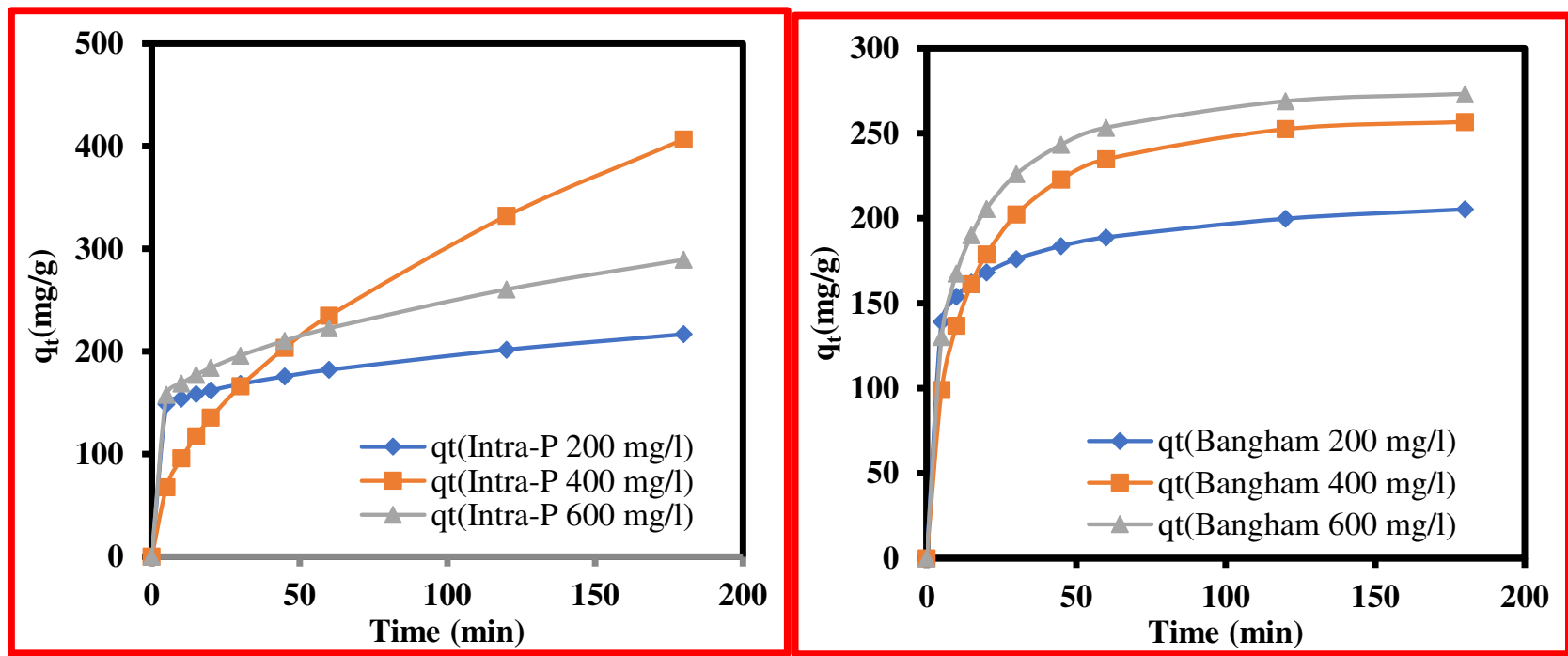

408

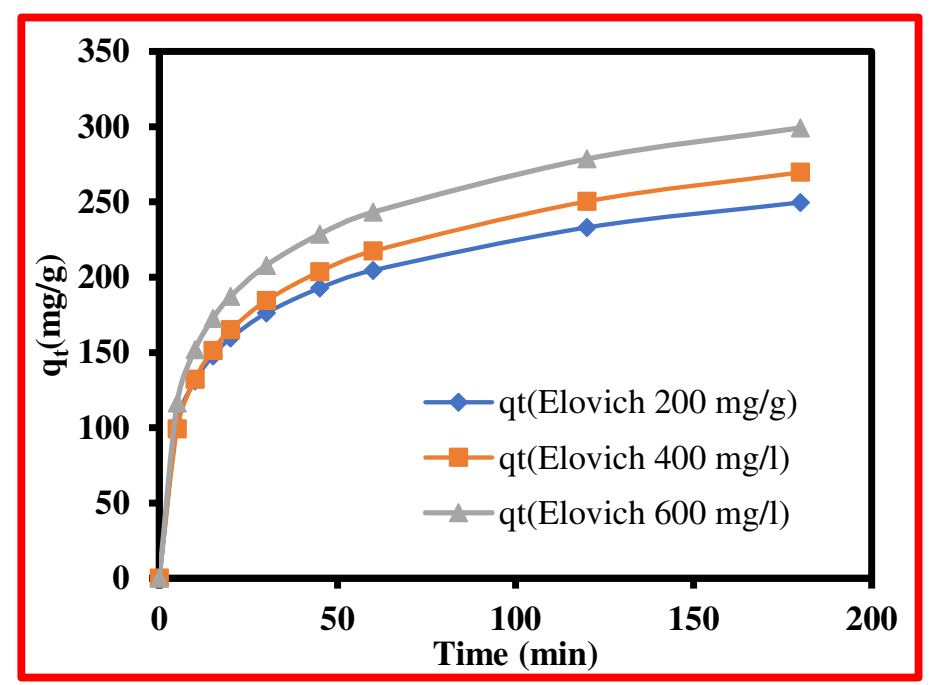

409 Fig. 8: The respective kinetic plots for PFO, PSO, Intraparticle diffusion, Elovich and Bangham model 
Table 7: Kinetic model parameters

\begin{tabular}{lllll}
\hline Pseudo-first order & Pseudo-second order & Elovich & Bangham & Intra-particle diffusion \\
\hline $\mathbf{2 0 0} \mathbf{~ m g / L}$ & & & & \\
$\mathrm{q}_{\mathrm{e}}=195.755$ & $\mathrm{q}_{\mathrm{e}}=205.482$ & $\alpha=100$ & $\mathrm{q}_{\mathrm{e}}=226.263$ & $\mathrm{k}_{\mathrm{id}}=6.118$ \\
$\mathrm{~K}_{1}=0.155$ & $\mathrm{~K}_{2}=1.4 \mathrm{E}-03$ & $\beta=0.024$ & $\mathrm{k}_{\mathrm{b}}=0.634$ & $\mathrm{C}=134.767$ \\
$\mathrm{R}^{2}=0.990$ & $\mathrm{R}^{2}=0.997$ & $\mathrm{R}^{2}=0.980$ & $\mathrm{n}=0.254$ & $\mathrm{R}^{2}=0.997$ \\
& & & $\mathrm{R}^{2}=0.999$ & \\
$\mathbf{4 0 0} \mathbf{~ m g / L}$ & & & & \\
$\mathrm{q}_{\mathrm{e}}=236.602$ & $\mathrm{q}_{\mathrm{e}}=269.533$ & $\alpha=76.389$ & $\mathrm{q}_{\mathrm{e}}=258.852$ & $\mathrm{k}_{\mathrm{id}}=30.317$ \\
$\mathrm{~K}_{1}=0.0817$ & $\mathrm{~K}_{2}=4.2 \mathrm{E}-04$ & $\beta=0.021$ & $\mathrm{k}_{\mathrm{b}}=0.172$ & $\mathrm{C}=0.01$ \\
$\mathrm{R}^{2}=0.994$ & $\mathrm{R}^{2}=0.996$ & $\mathrm{R}^{2}=0.992$ & $\mathrm{n}=0.641$ & $\mathrm{R}^{2}=0.922$ \\
& & & $\mathrm{R}^{2}=0.997$ & \\
$\mathbf{6 0 0} \mathbf{~ m g} / \mathbf{L}$ & & & & \\
$\mathrm{q}_{\mathrm{e}}=260.600$ & $\mathrm{q}_{\mathrm{e}}=283.808$ & $\alpha=100.00$ & $\mathrm{q}_{\mathrm{e}}=276.077$ & $\mathrm{k}_{\mathrm{id}}=11.773$ \\
$\mathrm{~K}_{1}=0.0683$ & $\mathrm{~K}_{2}=4.8 \mathrm{E}-04$ & $\beta=0.020$ & $\mathrm{k}_{\mathrm{b}}=0.264$ & $\mathrm{C}=131.564$ \\
$\mathrm{R}^{2}=0.988$ & $\mathrm{R}^{2}=0.997$ & $\mathrm{R}^{2}=0.994$ & $\mathrm{n}=0.549$ & $\mathrm{R}^{2}=0.988$ \\
& & & $\mathrm{R}^{2}=0.998$ & \\
\hline & & & &
\end{tabular}

412

$413 \quad 3.5 . \quad$ Thermodynamic studies

414 The effect of temperature on the adsorbent-adsorbate interaction during zinc ion uptake is 415 elucidated by the adsorption thermodynamics parameters (standard free energy, $\Delta \mathrm{G}^{\circ}$, standard 416 enthalpy, $\Delta \mathrm{H}^{\circ}$ and standard entropy, $\Delta \mathrm{S}^{\circ}$ ). The magnitude and sign convention of these 417 thermodynamics' parameters are key to explaining the various temperature effects. For 418 instance, the $\Delta \mathrm{G}^{\circ}$ value expresses the feasibility and spontaneity of the adsorption system, the $419 \Delta \mathrm{S}^{\circ}$ values informs of the degree of disorderliness of the system and the $\Delta \mathrm{H}^{\circ}$ value is related 420 to the heat content and energetic transfer within the adsorption system. The aforementioned 421 thermodynamics parameters are evaluated accordingly from Eqs. (9) to (10), while Kc is 
422 evaluated from Eq. (11) (Igwegbe, Oba, et al., 2020). Where R is the universal gas constant $423(8.314 \mathrm{~J} / \mathrm{mol} \mathrm{K})$ and $\mathrm{T}$ is the temperature $(\mathrm{K})$.

$424 \Delta \mathrm{G}^{\circ}=-\mathrm{RT} \ln \mathrm{K}_{\mathrm{c}}$

$425 \Delta \mathrm{G}^{\circ}=\Delta \mathrm{H}^{\circ}-\mathrm{T} \Delta \mathrm{S}^{\circ}$

$426 \quad \mathrm{~K}_{\mathrm{c}}=\frac{\mathrm{C}_{\mathrm{o}}-\mathrm{C}_{\mathrm{e}}}{\mathrm{C}_{\mathrm{o}}}$

427 The parameters presented in Table 8 shows positive $\Delta \mathrm{G}^{\circ}$ values and negative $\Delta \mathrm{S}^{\circ}$ value, thus 428 implies a non-spontaneous and less energetic nature of the process, respectively. According to 429 Saha et al. (2011), such observation suggests the temperature dependence of the ' $M A$ ' active sites and underscores the need for the application of external energy to the system. The positive $\Delta \mathrm{H}^{\circ}$ values obtained in the study provides further confirmation of the endothermicity of the adsorption process. Also, the relatively large $\Delta \mathrm{H}^{\circ}$ value obtained in the study is well within the physicochemical adsorption range and could be related to the strong bond obtainable from the ample carboxylic and carbonyl groups on the 'MA'.

Table 8: Thermodynamic parameters

\begin{tabular}{cccc}
\hline Temp. $(\mathrm{K})$ & $\Delta \mathrm{G}^{\mathrm{o}}\left(\mathrm{KJ}^{\mathrm{mol}}{ }^{-1}\right)$ & $\Delta \mathrm{H}^{\mathrm{o}}\left(\mathrm{KJ} \cdot \mathrm{mol}^{-1}\right)$ & $\Delta \mathrm{S}^{\mathrm{o}}\left(\mathrm{JK}^{-1} \cdot \mathrm{mol}^{-1}\right)$ \\
\hline 30 & 9.276 & & \\
50 & 11.378 & 61.241 & -4.875 \\
60 & 12.494 & &
\end{tabular}

3.6. Adsorption mechanism

The probable adsorption mechanism involved in the sorption of zinc ion onto ' $M A$ ' is discussed as follows;

440

(i) ion exchange and electrostatic interaction: This interaction resulted mainly from the

441 chemical bonds formed between negatively charged functional groups of the adsorbent and the 
positively charged Zn (II) ions [see Eqs. (6) \& (7)]. This mechanism is predominant when the $\mathrm{pH}>\mathrm{pH}$ PZC. The oxygenous (carboxylate, carbonyl and hydroxyl) surface groups of ' $M A$ ' were primarily responsible for the electrostatic interactions at favourable solution $\mathrm{pH}$.

(ii) Electron-donor-acceptor interaction: Due to the presence of H-donor functional groups $(-\mathrm{OH}$ and $-\mathrm{COOH})$ on ' $M A$ ', the mechanism of adsorption could be based on the complexation between the metal ion and the anionic $M A-\mathrm{COO}^{-}$conjugate (H-acceptor) (Scheme 1). Also, the carbonyl groups of ' $M A$ ' can engage in donor-acceptor interaction, during which the carbonyl groups of stronger dipole moment could donate the electron which would be accepted by the adsorbate (Mattson $\boldsymbol{e t}$ al., 1969).

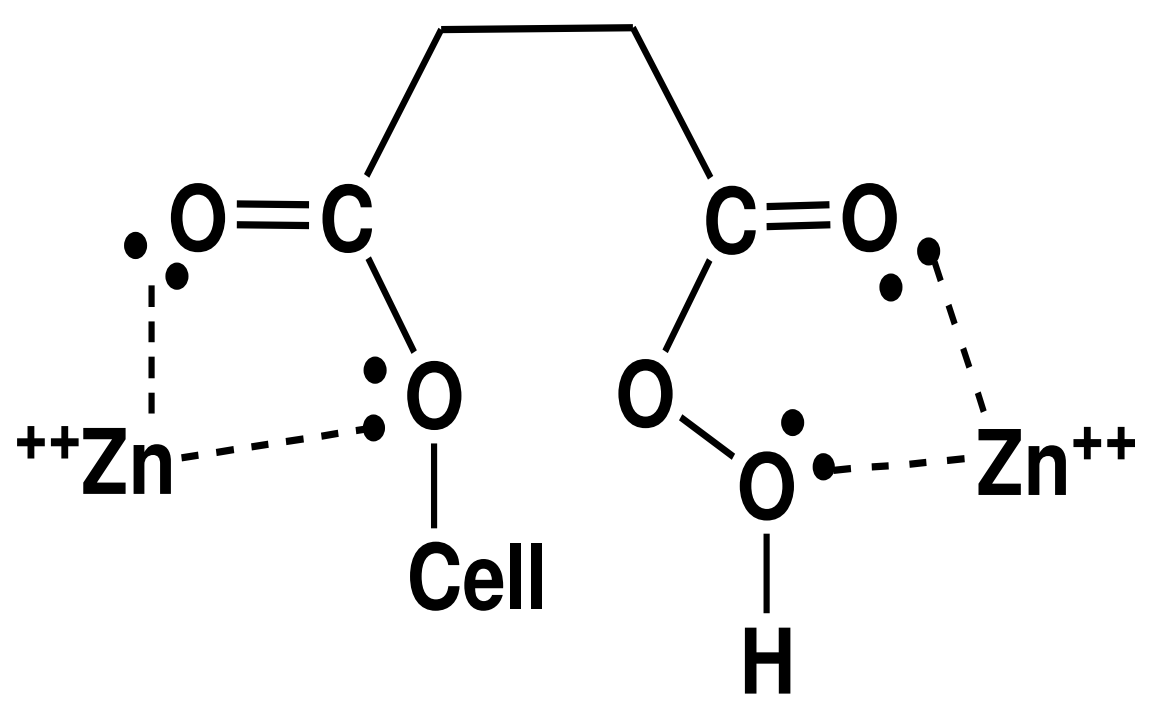
Scheme 1: Proposed mechanism for zinc ion adsorption onto ' $M A$ '.

\section{Conclusions}

A novel biosorbent, with high carboxyl content, was synthesized via the esterification reaction between highly cellulosic Alhagi root material $(A G)$ and succinic acid. The novel biosorbent was effective for aqueous zinc ion uptake. Using different adsorbent characterization tools (SEM, EDX, FTIR and $\mathrm{pH}_{\mathrm{pzc}}$ analyses) the acidic nature of ' $M A$ ' and its textural characteristics was explained. The equilibrium and kinetic modelling suggested a hybrid mix of monolayer- 
multilayer adsorption and intraparticle diffusion-controlled chemisorption, respectively. The entire sorption process was $\mathrm{pH}$-responsive, while electrostatic and electro-donor-acceptor interaction was established as the major uptake mechanism. Based on experimental findings, ' $M A$ ' has proven to be an excellent adsorbent for the removal due to the nature of its surface functional groups.

\section{Ethics declarations}

\section{Conflict of interest}

The authors declared no potential conflicts of interest concerning the research, authorship, and/or publication of this article.

\section{Ethical approval}

This work does not contain any studies with human participants or animals performed by any of the authors. The authors claim compliance with the ethical standards.

\section{References}

Abdelraheem, W. H., Komy, Z. R., \& Ismail, N. M. (2017). Electrochemical determination of $\mathrm{Cu}^{2+}$ complexation in the extract of E. crassipes by anodic stripping voltammetry. Arabian Journal of Chemistry, 10, S1105-S1110.

Abdelraheem, W. H., Rabia, M. K., \& Ismail, N. M. (2016). Evaluation of copper speciation in the extract of Eichhornia crassipes using reverse and forward/CLE voltammetric titrations. Arabian Journal of Chemistry, 9, S1670-S1678.

Abonyi, M., Aniagor, C., \& Menkiti, M. (2019). Effective Dephenolation of Effluent from Petroleum Industry Using Ionic-Liquid-Induced Hybrid Adsorbent. Arabian Journal for Science and Engineering, 44(12), 10017-10029. 
Adigun, O., Oninla, V., \& Babarinde, N. A. (2019). Application of sugarcane leaves as biomass in the removal of cadmium (II), lead (II) and zinc (II) ions from polluted water. International Journal of Energy and Water Resources, 3(2), 141-152.

Ahmad, M. F., Haydar, S., \& Quraishi, T. A. (2013). Enhancement of biosorption of zinc ions from aqueous solution by immobilized Candida utilis and Candida tropicalis cells. International Biodeterioration \& Biodegradation, 83, 119-128.

Al-Shaalan, N. H., Ali, I., ALOthman, Z. A., Al-Wahaibi, L. H., \& Alabdulmonem, H. (2019). High performance removal and simulation studies of diuron pesticide in water on MWCNTs. Journal of Molecular Liquids, 289, 111039.

Ali, I., Alharbi, O. M., ALOthman, Z. A., Alwarthan, A., \& Al-Mohaimeed, A. M. (2019). Preparation of a carboxymethylcellulose-iron composite for uptake of atorvastatin in water. International journal of biological macromolecules, 132, 244-253.

Ali, I., Alharbi, O. M., Alothman, Z. A., \& Badjah, A. Y. (2018). Kinetics, thermodynamics, and modeling of amido black dye photodegradation in water using $\mathrm{Co} / \mathrm{TiO} 2$ nanoparticles. Photochemistry and photobiology, 94(5), 935-941.

Aniagor, C., \& Menkiti, M. (2018). Kinetics and mechanistic description of adsorptive uptake of crystal violet dye by lignified elephant grass complexed isolate. Journal of Environmental Chemical Engineering, 6(2), 2105-2118.

Aniagor, C., \& Menkiti, M. (2019). Synthesis, modification and use of lignified bamboo isolate for the renovation of crystal violet dye effluent. Applied Water Science, 9(4), 77.

Aniagor, C. O., Igwegbe, C. A., Ighalo, J. O., \& Oba, S. N. (2021). Adsorption of doxycycline from aqueous media: A review. Journal of Molecular Liquids, 116124. doi:https://doi.org/10.1016/j.molliq.2021.116124

ANIAGOR, C. O., \& MENKITI, M. C. (2020). RELATIONAL DESCRIPTION OF AN ADSORPTION SYSTEM BASED ON ISOTHERM, ADSORPTION DENSITY, 

Sigma, 38(3), 1073-1098.

Awual, M. R. (2016). Solid phase sensitive palladium (II) ions detection and recovery using ligand based efficient conjugate nanomaterials. Chemical Engineering Journal, 300, 264-272.

Awual, M. R., Alharthi, N. H., Hasan, M. M., Karim, M. R., Islam, A., Znad, H., Hossain, M. A., Halim, M. E., Rahman, M. M., \& Khaleque, M. A. (2017). Inorganic-organic based novel nano-conjugate material for effective cobalt (II) ions capturing from wastewater. Chemical Engineering Journal, 324, 130-139.

Awual, M. R., Hasan, M. M., Asiri, A. M., \& Rahman, M. M. (2019). Novel optical composite material for efficient vanadium (III) capturing from wastewater. Journal of Molecular Liquids, 283, 704-712.

Awual, M. R., Hasan, M. M., Islam, A., Rahman, M. M., Asiri, A. M., Khaleque, M. A., \& Sheikh, M. C. (2019). Offering an innovative composited material for effective lead (II) monitoring and removal from polluted water. Journal of Cleaner Production, 231, $214-$ 223.

Badruddoza, A. Z. M., Shawon, Z. B. Z., Tay, W. J. D., Hidajat, K., \& Uddin, M. S. (2013). Fe3O4/cyclodextrin polymer nanocomposites for selective heavy metals removal from industrial wastewater. Carbohydrate polymers, 91(1), 322-332.

Barakat, M. (2011). New trends in removing heavy metals from industrial wastewater. Arabian Journal of Chemistry, 4(4), 361-377.

Chen, X., Lv, F., Lin, Y., Wang, Z., Meng, L., Zhang, Q., Zhang, W., \& Li, L. (2018). Structure evolution of polyethylene-plasticizer film at industrially relevant conditions studied by in-situ X-ray scattering: The role of crystal stress. European Polymer Journal, 101, 358-367. 
Dada, A., Olalekan, A., Olatunya, A., \& Dada, O. (2012). Langmuir, Freundlich, Temkin and Dubinin-Radushkevich isotherms studies of equilibrium sorption of $\mathrm{Zn} 2+$ unto phosphoric acid modified rice husk. IOSR Journal of Applied Chemistry, 3(1), 38-45.

Delgado, N., Capparelli, A., Navarro, A., \& Marino, D. (2019). Pharmaceutical emerging pollutants removal from water using powdered activated carbon: study of kinetics and adsorption equilibrium. Journal of environmental management, 236, 301-308.

Ebrahimi, A., Ehteshami, M., \& Dahrazma, B. (2015). Isotherm and kinetic studies for the biosorption of cadmium from aqueous solution by Alhaji maurorum seed. Process Safety and Environmental Protection, 98, 374-382.

Foo, K. Y., \& Hameed, B. H. (2010). Insights into the modeling of adsorption isotherm systems. Chemical Engineering Journal, 156(1), 2-10.

Freundlich, H. (1907). Über die adsorption in lösungen. Zeitschrift für physikalische Chemie, 57(1), 385-470.

Guo, X., \& Wang, J. (2019). A general kinetic model for adsorption: theoretical analysis and modeling. Journal of Molecular Liquids, 288, 111100.

Hashem, A., Al-Anwar, A., Nagy, N. M., Hussein, D. M., \& Eisa, S. (2016). Isotherms and kinetic studies on adsorption of $\mathrm{Hg}$ (II) ions onto Ziziphus spina-christi L. from aqueous solutions. Green Processing and Synthesis, 5(2), 213-224.

Hashem, A., Aniagor, C., Hussein, D., \& Farag, S. (2021). Application of novel butane-1, 4dioic acid-functionalized cellulosic biosorbent for aqueous cobalt ion sequestration. Cellulose, 1-17.

Hashem, A., ANIAGOR, C. O., Nasr, M., \& Abou-Okeil, A. (2021). Efficacy of treated sodium alginate and activated carbon fibre for $\mathrm{Pb}(\mathrm{II})$ adsorption. International journal of biological macromolecules, 1-16. doi:https://doi.org/10.1016/j.ijbiomac.2021.02.067 
Hashem, A., Badawy, S., Farag, S., Mohamed, L., Fletcher, A., \& Taha, G. (2020). Non-linear adsorption characteristics of modified pine wood sawdust optimised for adsorption of Cd (II) from aqueous systems. Journal of Environmental Chemical Engineering, 103966

Hashem, A., \& Badawy, S. M. (2015). Sesbania sesban L. biomass as a novel adsorbent for removal of $\mathrm{Pb}$ (II) ions from aqueous solution: non-linear and error analysis. Green Processing and Synthesis, 4(3), 179-190.

Hashem, A., Fletcher, A., Younis, H., Mauof, H., \& Abou-Okeil, A. (2020). Adsorption of Pb (II) ions from contaminated water by 1, 2, 3, 4-butanetetracarboxylic acid-modified microcrystalline cellulose: Isotherms, kinetics, and thermodynamic studies. International journal of biological macromolecules, 164, 3193-3203.

Hashem, A., Hussein, H. A., Sanousy, M. A., Adam, E., \& Saad, E. E. (2011). Monomethylolated thiourea-sawdust as a new adsorbent for removal of $\mathrm{Hg}$ (II) from contaminated water: equilibrium kinetic and thermodynamic studies. Polymer-Plastics Technology and Engineering, 50(12), 1220-1230.

Hashem, A., Nasr, M., Fletcher, A., \& Mohamed, L. A. (2020). Aminated acrylic fabric waste derived sorbent for Cd (II) ion removal from aqueous solutions: mechanism, equilibria and kinetics. Journal of Polymers and the Environment, 1-12.

Ighalo, J. O., Tijani, I. O., Ajala, J., Ayandele, F. O., Eletta, O., \& Adeniyi, A. G. (2020). Competitive Biosorption of $\mathrm{Pb}$ (II) and $\mathrm{Cu}$ (II) by Functionalised Micropogonias undulates Scales. Recent Innovations in Chemical Engineering, 13, 1-12.

Igwegbe, C. A., Oba, S. N., Aniagor, C. O., Adeniyi, A. G., \& Ighalo, J. O. (2020). Adsorption of ciprofloxacin from water: a comprehensive review. Journal of Industrial and Engineering Chemistry. 
579 Igwegbe, C. A., Onukwuli, O. D., Ighalo, J. O., \& Okoye, P. U. (2020). Adsorption of cationic dyes on Dacryodes edulis seeds activated carbon modified using phosphoric acid and sodium chloride. Environmental Processes, 7(4), 1151-1171.

582

583

584

585

586

587

588

589

590

591

592

593

594

595

596

597

598

599

600

601

Jagaba, A., Kutty, S., Khaw, S., Lai, C., Isa, M., Baloo, L., Lawal, I., Abubakar, S., Umaru, I., \& Zango, Z. (2020). Derived hybrid biosorbent for zinc (II) removal from aqueous solution by continuous-flow activated sludge system. Journal of Water Process Engineering, 34, 101152.

Kapoor, A., \& Yang, R. (1989). Correlation of equilibrium adsorption data of condensible vapours on porous adsorbents. Gas Separation \& Purification, 3(4), 187-192.

Khair, U., Fahmi, H., Al Hakim, S., \& Rahim, R. (2017). Forecasting error calculation with mean absolute deviation and mean absolute percentage error. Paper presented at the Journal of Physics: Conference Series.

Khalil, M., Hashem, A., \& Hebeish, A. (1990). Carboxymethylation of maize starch. StarchStärke, 42(2), 60-63.

Khan, A., Ataullah, R., \& Al-Haddad, A. (1997). Equilibrium adsorption studies of some aromatic pollutants from dilute aqueous solutions on activated carbon at different temperatures. Journal of colloid and interface science, 194(1), 154-165.

King, P., Anuradha, K., Lahari, S. B., Kumar, Y. P., \& Prasad, V. (2008). Biosorption of zinc from aqueous solution using Azadirachta indica bark: equilibrium and kinetic studies. J Hazard Mater, 152(1), 324-329.

Komy, Z. R., Abdelraheem, W. H., \& Ismail, N. M. (2013). Biosorption of Cu2+ by Eichhornia crassipes: Physicochemical characterization, biosorption modeling and mechanism. Journal of King Saud University-Science, 25(1), 47-56. 
602

603

604

605

606

607

608

609

610

611

612

613

614

615

616

617

618

619

620

621

622

623

624

625

Kumar, K. V., Porkodi, K., \& Rocha, F. (2008). Comparison of various error functions in predicting the optimum isotherm by linear and non-linear regression analysis for the sorption of basic red 9 by activated carbon. J Hazard Mater, 150(1), 158-165.

Langmuir, I. (1916). The constitution and fundamental properties of solids and liquids. Part I. Solids. Journal of the American chemical society, 38(11), 2221-2295.

Liu, X., Chen, Z.-Q., Han, B., Su, C.-L., Han, Q., \& Chen, W.-Z. (2018). Biosorption of copper ions from aqueous solution using rape straw powders: optimization, equilibrium and kinetic studies. Ecotoxicology and Environmental Safety, 150, 251-259.

Luef, E., Prey, T., \& Kubicek, C. P. (1991). Biosorption of zinc by fungal mycelial wastes. Applied Microbiology and biotechnology, 34(5), 688-692.

Marquardt, D. W. (1963). An algorithm for least-squares estimation of nonlinear parameters. Journal of the society for Industrial and Applied Mathematics, 11(2), 431-441.

Matouq, M., Jildeh, N., Qtaishat, M., Hindiyeh, M., \& Al Syouf, M. Q. (2015). The adsorption kinetics and modeling for heavy metals removal from wastewater by Moringa pods. Journal of Environmental Chemical Engineering, 3(2), 775-784.

Mattson, J. A., Mark Jr, H. B., Malbin, M. D., Weber Jr, W. J., \& Crittenden, J. C. (1969). Surface chemistry of active carbon: specific adsorption of phenols. Journal of colloid and interface science, 31(1), 116-130.

Menkiti, M., Abonyi, M., \& Aniagor, C. (2018). Process Equilibrium, Kinetics, and Mechanisms of Ionic-Liquid Induced Dephenolation of Petroleum Effluent. Water Conservation Science and Engineering, 3(3), 205-220.

Menkiti, M., \& Aniagor, C. (2018). Parametric studies on descriptive isotherms for the uptake of crystal violet dye from aqueous solution onto lignin-rich adsorbent. Arabian Journal for Science and Engineering, 43(5), 2375-2392. 
Menkiti, M., Aniagor, C., Agu, C., \& Ugonabo, V. (2018). Effective adsorption of crystal violet dye from an aqueous solution using lignin-rich isolate from elephant grass. Water Conservation Science and Engineering, 3(1), 33-46.

Ng, J., Cheung, W., \& McKay, G. (2002). Equilibrium studies of the sorption of Cu (II) ions onto chitosan. Journal of colloid and interface science, 255(1), 64-74.

Noh, J. S., \& Schwarz, J. A. (1990). Effect of HNO3 treatment on the surface acidity of activated carbons. Carbon, 28(5), 675-682.

Oba, S. N., Ighalo, J. O., Aniagor, C. O., \& Igwegbe, C. A. (2021). Removal of ibuprofen from aqueous media by adsorption: A comprehensive review. Science of the total environment, 146608. doi:https://doi.org/10.1016/j.scitotenv.2021.146608

Paduraru, C., Tofan, L., Teodosiu, C., Bunia, I., Tudorachi, N., \& Toma, O. (2015). Biosorption of zinc (II) on rapeseed waste: equilibrium studies and thermogravimetric investigations. Process Safety and Environmental Protection, 94, 18-28.

Redlich, O., \& Peterson, D. L. (1959). A useful adsorption isotherm. Journal of physical chemistry, 63(6), 1024-1024.

Rivas, F., Beltrán, F., Gimeno, O., Frades, J., \& Carvalho, F. (2006). Adsorption of landfill leachates onto activated carbon: equilibrium and kinetics. J Hazard Mater, 131(1-3), 170-178.

Saha, P., \& Chowdhury, S. (2011). Insight into adsorption thermodynamics. Thermodynamics, $16,349-364$.

Sasmal, S., Goud, V. V., \& Mohanty, K. (2012). Characterization of biomasses available in the region of North-East India for production of biofuels. Biomass and Bioenergy, 45, 212220.

Schweitzer, L., \& Noblet, J. (2018). Water Contamination and Pollution. 261-290. doi:10.1016/b978-0-12-809270-5.00011-x 
Shahat, A., Hassan, H. M., Azzazy, H. M., El-Sharkawy, E., Abdou, H. M., \& Awual, M. R. (2018). Novel hierarchical composite adsorbent for selective lead (II) ions capturing from wastewater samples. Chemical Engineering Journal, 332, 377-386.

Shahat, A., Hassan, H. M., El-Shahat, M., El Shahawy, O., \& Awual, M. R. (2018). Visual nickel (II) ions treatment in petroleum samples using a mesoporous composite adsorbent. Chemical Engineering Journal, 334, 957-967.

Temkin, M. (1940). Kinetics of ammonia synthesis on promoted iron catalysts. Acta physiochim. URSS, 12, 327-356.

Toth, J. (1971). State equation of the solid-gas interface layers. Acta chim. hung., 69, 311-328.

Vargas, A. M., Cazetta, A. L., Martins, A. C., Moraes, J. C., Garcia, E. E., Gauze, G. F., Costa, W. F., \& Almeida, V. C. (2012). Kinetic and equilibrium studies: Adsorption of food dyes Acid Yellow 6, Acid Yellow 23, and Acid Red 18 on activated carbon from flamboyant pods. Chemical Engineering Journal, 181, 243-250.

Wang, G., Chang, Q., Zhang, M., \& Han, X. (2013). Effect of pH on the removal of Cr (III) and $\mathrm{Cr}$ (VI) from aqueous solution by modified polyethyleneimine. Reactive and Functional Polymers, 73(11), 1439-1446.

Wang, L., Shi, C., Pan, L., Zhang, X., \& Zou, J.-J. (2020). Rational design, synthesis, adsorption principles and applications of metal oxide adsorbents: a review. Nanoscale, 12(8), 4790-4815.

Wang, X. S., Qin, Y., \& Li, Z. F. (2006). Biosorption of zinc from aqueous solutions by rice bran: kinetics and equilibrium studies. Separation science and technology, 41(4), 747756.

Wołowiec, M., Komorowska-Kaufman, M., Pruss, A., Rzepa, G., \& Bajda, T. (2019). Removal of heavy metals and metalloids from water using drinking water treatment residuals as adsorbents: A review. Minerals, 9(8), 487. 
676 Yan, Y., Xu, X., Shi, C., Yan, W., Zhang, L., \& Wang, G. (2019). Ecotoxicological effects and 677 accumulation of ciprofloxacin in Eichhornia crassipes under hydroponic conditions. 678 Environ Sci Pollut Res Int, 26(29), 30348-30355. doi:10.1007/s11356-019-06232-5

679 Zhuang, S., \& Wang, J. (2019). Removal of cobalt ion from aqueous solution using magnetic 680 graphene oxide/chitosan composite. Environmental Progress \& Sustainable Energy, 681 38(s1), S32-S41.

682 Zhuang, S., Zhu, K., \& Wang, J. (2020). Fibrous chitosan/cellulose composite as an efficient 683 adsorbent for Co ( II ) removal. Journal of Cleaner Production, 124911. 